\section{Check for updates}

Cite this: Mater. Adv., 2021

2, 907

Received 27th October 2020,

Accepted 16th January 2021

DOI: 10.1039/d0ma00837k

rsc.li/materials-advances

\title{
Plasmonic $\mathrm{Cu}_{2-x} \mathrm{~S}$ nanoparticles: a brief introduction of optical properties and applications
}

\author{
Lihui Chen, (D)*a Haifeng Hu, (D) ${ }^{a}$ Yuzhou Chen, (D) ${ }^{a}$ Jing Gao (D) and \\ Guohua Li (D)*ab
}

$\mathrm{Cu}_{2-x} \mathrm{~S}(0<x \leq 1)$ nanoparticles (NPs) heavily doped with copper vacancies can support localized surface plasmon resonance (LSPR) in near-infrared and mid-infrared spectral wavelengths, causing resonant absorption, scattering of photons and near-surface electric field enhancement. In this review, we will firstly discuss the fundamentals of optical responses in $\mathrm{Cu}_{2-x} \mathrm{~S}$ and their numerical modeling, followed by the highlights of their flexible LSPR manipulation and LSPR correlated photoluminescence. Furthermore, we will present recently exploited applications based on the LSPR of $\mathrm{Cu}_{2-x} \mathrm{~S} N P$ s. Finally, we will give a brief conclusion of the review and discuss the remaining open issues relating to the particle synthesis, chemistries, physics, optics and industrial applications, and we will propose some possible further research directions as well.

\section{Introduction}

Over last two decades, there has been a great development in the field of localized surface plasmon resonance (LSPR). LSPR can be defined as nanoparticles (NPs) much smaller than the wavelength of the incident light in size, exhibiting collective oscillation of free carriers when the frequency of electromagnetic wave matches the frequency of free carriers oscillating

${ }^{a}$ College of Chemical Engineering, Zhejiang University of Technology, 18, Chaowang Road, Hangzhou 310014, China. E-mail: lihuichen@zjut.edu.cn

${ }^{b}$ State Key Breeding Base of Green Chemistry Synthesis Technology, Zhejiang University of Technology, 18, Chaowang Road, Hangzhou 310032, China. E-mail: nanozjut@zjut.edu.cn

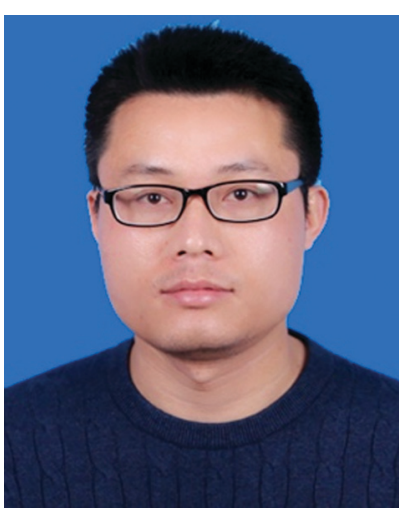

Lihui Chen
Lihui Chen received his PhD degree in 2016 at Kyoto University under the supervision of Prof. Toshiharu Teranishi, then he performed postdoctoral research work at Institute for Chemical Research, Kyoto University. Afterwards, he joined Zhejiang University of Technology as an assistant research fellow in 2018. His research interests focus on the synthesis of plasmonic metal and semiconductor nanoparticles and their applications in photo(electro)catalysis.

against the restoring force of oppositely-charged carriers. ${ }^{1}$ Noble metal NPs such as $\mathrm{Au}$ and $\mathrm{Ag}$ are the most systematically exploited plasmonic materials and mainly exhibit their LSPRs in the visible region. ${ }^{2}$ Recently, it has been disclosed that LSPR emerges not only in metals but also in heavily doped semiconductors with appreciable free carrier density, including aliovalent doped/selfdoped metal oxides, metal chalcogenides, metal nitrides and many others. ${ }^{3}$ For example, tin doped indium oxide (ITO), ${ }^{4}$ aluminum doped zinc oxide (AZO) ${ }^{5}$ niobium doped titanium oxide (NTO), ${ }^{6}$ oxygen-deficient molybdenum oxide $\left(\mathrm{MoO}_{3-x}\right)^{7,8}$ and tungsten oxide $\left(\mathrm{WO}_{3-x}\right),{ }^{9}$ titanium nitride $\left(\mathrm{Ti}_{x} \mathrm{~N}\right)^{10}$ as well as nonstoichiometric copper chalcogenide $\left(\mathrm{Cu}_{2-x} \mathrm{E}, \mathrm{E}=\mathrm{S}\right.$, Se and $\mathrm{Te})^{11-18}$ NPs exhibit intense LSPR. In particular, copper vacancy (hole) doped $\mathrm{Cu}_{2-x} \mathrm{~S}$ NPs have attracted numerous attention

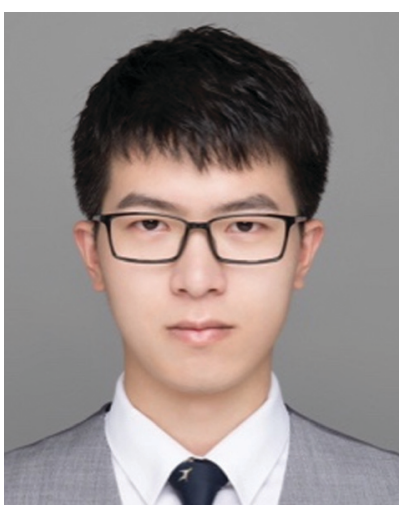

Haifeng $\mathrm{Hu}$
Haifeng $H u$ received his $B E$ degree at Hebei University of Technology in 2018. Now, he works as a master candidate at Zhejiang University of Technology (with Dr Lihui Chen and Prof. Guohua Li). His research interests are focused on the fabrication of metal sulfide nanoparticles and their cation exchange dynamics. 
since the pioneering work by Zhao et al. in 2009, where the oscillation of holes generated in valence band results in strong absorption and scattering of incident light. ${ }^{19}$ Because of lower order of magnitude of carrier density $\left(N_{\mathrm{h}} \approx 10^{20}-10^{22} \mathrm{~cm}^{-3}\right)$ with respect to noble metals $\left(N_{\mathrm{e}} \approx 10^{23} \mathrm{~cm}^{-3}\right), \mathrm{Cu}_{2-x} \mathrm{~S}$ NPs support LSPR responses in near-infrared (NIR) and mid-infrared (MIR) regions. ${ }^{20-23}$ Unlike noble metals with restricted carrier density, once the size, morphology and the surrounding medium is fixed, the LSPR response is locked and cannot be flexibly adjusted. In $\mathrm{Cu}_{2-x} \mathrm{~S}$ NPs, ever a minor variation of carrier density has a strong effect on the spectral position and strength of the LSPR. This allows for a controllable LSPR tuning over a wide spectral range, either during the synthesis or post-treatment, making the $\mathrm{Cu}_{2-x} \mathrm{~S}$ NPs very fascinating in a manifold of research fields. $^{24-30}$

In addition to variable carrier density, another advantage of $\mathrm{Cu}_{2-x} \mathrm{~S}$ over noble metals is the existence of various crystal structures and stoichiometrics, varying from the most copperrich high/low chalcocite $\mathrm{Cu}_{2} \mathrm{~S}$ to the most copper-poor covellite CuS. ${ }^{31}$ Due to the absence of any free holes, the full stoichiometric $\mathrm{Cu}_{2} \mathrm{~S}$ is LSPR inactive, while the nonstoichiometric $\mathrm{Cu}_{2-x} \mathrm{~S}$ are all in LSPR-active state. ${ }^{11,19}$ The LSPRs of $\mathrm{Cu}_{2-x} \mathrm{~S}$ NPs are highly dependent on their crystal structures. As previously demonstrated, djurleite $\mathrm{Cu}_{1.94} \mathrm{~S}$ and digenite $\mathrm{Cu}_{1.8} \mathrm{~S}$ nanodisks

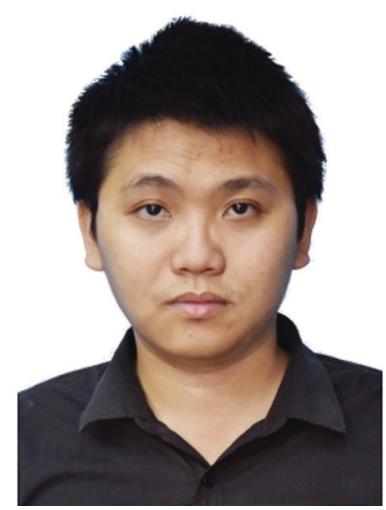

Yuzhou Chen
Yuzhou Chen received his $B E$ degree at Wuhan Institute of Technology in 2019. Now, he is a master candidate at Zhejiang University of Technology and works with Dr Lihui Chen and Prof. Guohua Li. His research interests are focused on the posttreatment of metal oxides for electronic devices and metal sulfides for photocatalysis.

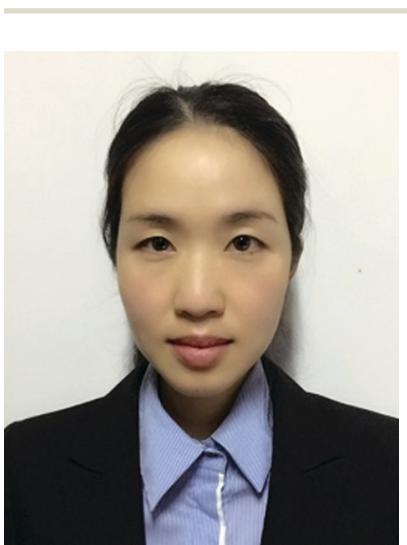

Jing Gao
Jing Gao received her $\mathrm{PhD}$ degree in 2012 at University of Glasgow under the supervision of Prof. Leroy Cronin, after that she worked as a postdoctor at University of Tokyo in 2014. She is now a full professor at Zhejiang University of Technology and her current research mainly focuses on the synthesis of nanocomposites and their applications in supercapacitors and photoelectrocatalysts.
(NDs) show two distinct LSPR oscillation peaks assigned to outof-plane mode and in-plane mode in the NIR and MIR regions, respectively, while roxbyite $\mathrm{Cu}_{1.8} \mathrm{~S}$ NDs and covellite CuS NDs only exhibit one oscillation peak assigned to in-plane mode in NIR region. ${ }^{32-34}$ Besides the crystal structure, another crucial parameter is the morphology. Indeed, morphology dependent LSPR has been demonstrated in $\mathrm{Cu}_{2-x} \mathrm{~S}$ nanospheres, nanodisks and nanorods. ${ }^{32,35}$ Thanks to the tunable LSPR, the $\mathrm{Cu}_{2-x} \mathrm{~S}$ NPs have been well exploited in photothermal therapy, photocatalysis, sensing, switchable magnetic probe, two-photon upconversion and many others. $^{3,24}$

Herein, we present a review on the emerging $\mathrm{Cu}_{2-x} \mathrm{~S}$ NPs, particularly their optical responses and LSPR related applications. In the first section, we start the introduction of crystal structures and stoichiometrics of $\mathrm{Cu}-\mathrm{S}$ system. Following this subsection is a discussion on the hole generation in the valence band of intrinsically unstable $\mathrm{Cu}_{2} \mathrm{~S}$. Then, we introduce an optical modeling of $\mathrm{Cu}_{2-x} \mathrm{~S}$ for better understanding of their LSPR and it is followed by vigorous discussion on the flexible manipulation of LSPR in $\mathrm{Cu}_{2-x} \mathrm{~S}$ via hole density tuning, crystal structure control and transformation as well as morphology control. Furthermore, we briefly discuss the relationship between LSPR and photoluminescence of $\mathrm{Cu}_{2-x} \mathrm{~S}$. In the second section, we introduce recently well exploited plasmonic applications including photoacoustic imaging and photothermal therapy, photocatalytic organic synthesis, photo(electro)catalytic water splitting, twophoton upconversion as well as SERS probe endowed by the LSPR of $\mathrm{Cu}_{2-x} \mathrm{~S}$. In the third section, we give a short summary of this review and we emphasize some important open questions relevant to the $\mathrm{Cu}_{2-x} \mathrm{~S}$ synthesis, chemistries, physics and industrial applications.

\section{Optical responses}

Since the optical responses of $\mathrm{Cu}_{2-x} \mathrm{~S}$ NPs are determined not only by their crystal structure and stoichiometry but also by the morphology. In this section, we firstly introduce the crystal structures and $\mathrm{Cu}-\mathrm{S}$ system of copper sulfide, then we give a brief discussion on the generation of copper vacancies in the

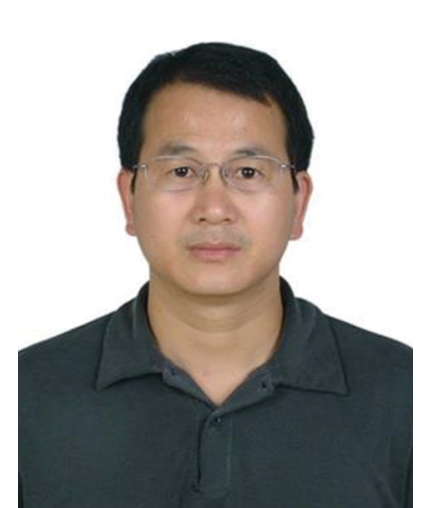

Guohua Li
Guohua Li received his PhD degree in 2002 at Central South University, after that he worked as a postdoctor at Zhejiang University. He joined Newcastle University as a visiting scholar in 2008. Currently, he is a full professor at Zhejiang University of Technology and his research mainly focuses on the synthesis of metal carbides for electrocatalytic hydrogen evolution and metal sulfides/oxides for photocatalytic pollutant degradation. 
valence band of fully stoichiometric $\mathrm{Cu}_{2} \mathrm{~S}$. After that, an optical modeling for $\mathrm{Cu}_{2-x} \mathrm{~S}$ to better understand the origin of the LSPR is provided and it is followed by an elaborate discussion on the flexible manipulation of LSPR in $\mathrm{Cu}_{2-x} \mathrm{~S}$ NPs via hole density tuning, crystal structure control and transformation as well as morphology control. Furthermore, the relationship between LSPR and photoluminescence of $\mathrm{Cu}_{2-x} \mathrm{~S}$ is discussed.

\subsection{Crystal structures and stoichiometries of $\mathrm{Cu}-\mathrm{S}$ system}

In $\mathrm{Cu}-\mathrm{S}$ system, the sulfur $3 \mathrm{~s}$ and $3 \mathrm{p}$ orbitals can strongly hybridize with copper $3 p$ and $4 \mathrm{~s}$ orbitals, resulting in more covalent character. Moreover, the low size and electronegativity differences between sulfur and copper, the ability to form S-S bonds and the probability of $\mathrm{Cu}-\mathrm{Cu}$ bonds within the structure, allow for an abundance of crystal structures and stoichiometrics in copper sulfide, varying from most copper-sufficient chalcocite $\mathrm{Cu}_{2.0-1.94} \mathrm{~S}$, djurleite $\mathrm{Cu}_{1.97-1.94} \mathrm{~S}$, to roxbyite $\mathrm{Cu}_{1.78-1.81} \mathrm{~S}$, digenite $\mathrm{Cu}_{1.8} \mathrm{~S}$ and anilite $\mathrm{Cu}_{1.75} \mathrm{~S}$, and to most copperdeficient covellite CuS (Table 1). ${ }^{3,31}$ The chalcocite phase exists in three different forms at different temperatures: low chalcocite phase is formed at $T>104{ }^{\circ} \mathrm{C}$, high chalcocite phase is at $104{ }^{\circ} \mathrm{C}<T<436{ }^{\circ} \mathrm{C}$ and cubic chalcocite phase is at $T \geq 436{ }^{\circ} \mathrm{C}$. Among these three structures, low chalcocite phase is the most stable one at room temperature. ${ }^{36}$ However, at or above $105{ }^{\circ} \mathrm{C}$, the low chalcocite phase transforms into high chalcocite phase, which is a solid-liquid hybrid phase. ${ }^{37}$ Djurleite phase is similar to low chalcocite phase, because of its monoclinic structure with a slightly decreased copper content. Both the djurleite and low chalcocite phase are very common species and are usually coexisted. ${ }^{38,39}$ The djurleite phase was initially discovered by Djurle and later was established as the mineral djurleite in his honor. ${ }^{40,41}$ The unit cell content of djurleite is $\mathrm{Cu}_{62} \mathrm{~S}_{32}\left(\mathrm{Cu}_{1.94} \mathrm{~S}\right)$ with 62 copper atoms in the structure, where 52 copper atoms are in a triangular coordination with sulfur, 9 copper atoms are in a tetrahedral coordination, and the last one is in a linear coordination. ${ }^{39}$ When an extra $\mathrm{Cu}$ atom is added to the structure, the unit cell content becomes $\mathrm{Cu}_{63} \mathrm{~S}_{32}$ $\left(\mathrm{Cu}_{1.97} \mathrm{~S}\right)$, exhibiting the higher and lower limit of $\mathrm{Cu}_{1.94-1.97} \mathrm{~S}$ for djurleite. Another case with lower $\mathrm{Cu}: \mathrm{S}$ stoichiometric ratio $(1.8: 1)$ is digenite phase in the crystal structure. Bulk digenite $\mathrm{Cu}_{1.8} \mathrm{~S}$ has three polymorphs depending on the temperature: high-temperature phase with face-centered cubic sulfur anion structure, which is stable at $T>73 \pm 3{ }^{\circ} \mathrm{C}$, low-temperature phase also has face-centered cubic symmetry of sulfur anion

Table $1 \mathrm{CU}-\mathrm{S}$ system: mineral name, stoichiometry and their corresponding crystal structures (data extracted from ref. 3, 31 and 57)

\begin{tabular}{llll}
\hline Mineral name & Stoichiometry & s packing & Crystal structure \\
\hline Low chalcocite $(\alpha)$ & $\mathrm{Cu}_{2.0-1.997} \mathrm{~S}$ & hcp & Monoclinic \\
High chalcocite $(\beta)$ & $\mathrm{Cu}_{2.0-1.94} \mathrm{~S}$ & hcp & Hexagonal \\
Cubic chalcocite $(\gamma)$ & $\mathrm{Cu}_{2} \mathrm{~S}$ & fcc & Cubic \\
Djurleite & $\mathrm{Cu}_{1.97-1.94} \mathrm{~S}$ & hcp & Monoclinic \\
Digenite & $\mathrm{Cu}_{1.8} \mathrm{~S}$ & fcc & Cubic \\
Roxbyite & $\mathrm{Cu}_{1.81} \mathrm{~S}\left(\mathrm{Cu}_{58} \mathrm{~S}_{32}\right)$ & hcp & Triclinic \\
Anilite & $\mathrm{Cu} \mathrm{u}_{1.75} \mathrm{~S}\left(\mathrm{Cu}_{7} \mathrm{~S}_{4}\right)$ & fcc & Orthorhombic \\
Covellite & $\mathrm{CuS}$ & hcp & Hexagonal
\end{tabular}

structure but different lattice constants and metastable rhombohedral phase obtained by cooling from $73 \pm 3{ }^{\circ} \mathrm{C}$ resembles high chalcocite, with one copper atom located at four equivalent positions in each sulfur tetrahedron. ${ }^{42,43}$ These three structures are close related to each other, and therefore, phase identification of $\mathrm{Cu}_{1.8} \mathrm{~S}$ NPs remains a challenge. ${ }^{44}$ Roxbyite phase $\mathrm{Cu}_{1.81} \mathrm{~S}$ $\left(\mathrm{Cu}_{58} \mathrm{~S}_{32}\right)$ is just as complex in its entirety as the structures of low chalcocite and djurleite phase. ${ }^{45,46}$ It has been described that, it possesses a triclinic unit cell with 90 atoms, constructing a distorted hexagonal close packing of 32 sulfur atoms with 58 individual copper atoms occupying triangular coordination with sulfur. Other layers sandwiched between the close packed sulfur layers composed of double or split layers of $\mathrm{Cu}$ atoms. Some of which have two-fold linear coordination, but mostly they have three-fold triangular and four-fold tetrahedral coordination. ${ }^{46}$ The roxbyite phase is unusual in bulk forms but has been readily synthesized in NPs. ${ }^{23,47,48}$ Anilite $\mathrm{Cu}_{1.75} \mathrm{~S}\left(\mathrm{Cu}_{7} \mathrm{~S}_{4}\right)$ phase has an orthorhombic crystal system, where the sulfur atoms adopt approximately face-centered cubic arrangement and the copper atoms occupy the interstices. ${ }^{49}$ In the orthorhombic unit cell of 28 copper atoms, 20 of which are in triangular coordination and 8 are in tetrahedral coordination with sulfur. ${ }^{50}$ Moreover, according to the theoretical study based on DFT theory, anilite phase was shown to be the most stable structure among the known $\mathrm{Cu}_{2-x} \mathrm{~S}$ phases. ${ }^{51}$ The most Cu-deficient covellite CuS phase has a unique layered structure in spite of simplest stoichiometry, where its copper atoms locate in two different environments: planar trigonal $\mathrm{CuS}_{3}$ layer are sandwiched by two tetrahedral $\mathrm{CuS}_{4}$ layers along the $c$-axis, with the triple layers connected to adjacent triple layers through disulfide (S-S) covalent bonds. ${ }^{52}$ Another description of covellite CuS is that it is composed of alternating $\mathrm{CuS}_{3}-$ $\mathrm{CuS}_{3}-\mathrm{CuS}_{3}$ layers and S-S layers along the $c$-axis. ${ }^{53}$ It is worth noting that CuS forms this unique structure, rather than another simpler available structures, is due to more energetically favorable covalently bonding between sulfur atoms, than bonding to copper atoms. ${ }^{54}$ The unique crystallographic feature in covellite CuS phase allows for an intercalation and a reaction of alkali metal cations such as $\mathrm{Li}^{+}$between the $\mathrm{S}-\mathrm{Cu}-\mathrm{S}$ layers, endowing CuS NPs as a promising electrode material for Li-ion battery. ${ }^{55}$ The above discussed crystal structures of $\mathrm{Cu}_{2-x} \mathrm{~S}$ can be catalogued by either asymmetric hcp (hexagonal close packing) or fcc (facecentered cubic) of sulfur anions, with copper cations occupying interstitial spaces in the sulfur lattice. ${ }^{56}$ The crystal structures of important copper sulfide phases are shown in Fig. 1a-h. However, The Cu-S crystal systems mentioned here would not be complete without the other less discussed crystal structures such as geerite $\mathrm{Cu}_{1.6} \mathrm{~S}$, spionkopite $\mathrm{Cu}_{1.39} \mathrm{~S}$, yarrowite $\mathrm{Cu}_{1.12} \mathrm{~S}$ and villamanitite $\mathrm{CuS}_{2}$, which are possible in the bulk forms but are somewhat unusual in NPs. ${ }^{57}$ In contrast to electron-based noble metals, LSPR responses in $\mathrm{Cu}_{2-x} \mathrm{~S}$ originate from collective oscillation of free holes in valence band. Therefore, the fully stoichiometric $\mathrm{Cu}_{2} \mathrm{~S}$ is LSPR inactive due to the absence of any free holes, while the nonstoichiometric $\mathrm{Cu}_{2-x} \mathrm{~S}$ are all in LSPR-active state. Furthermore, the LSPR responses in $\mathrm{Cu}_{2-x} \mathrm{~S}$ are highly sensitive to both of the crystal structure and the $\mathrm{Cu} / \mathrm{S}$ stoichiometry. Among the LSPR-active $\mathrm{Cu}_{2-x} \mathrm{~S}$, it is worth noting that, the aforementioned 
a

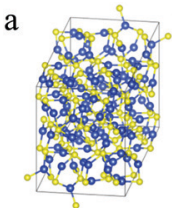

e

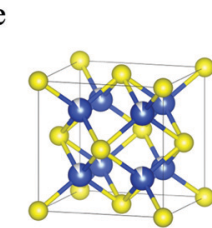

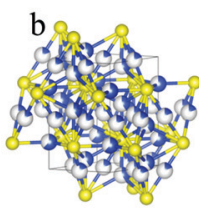

f

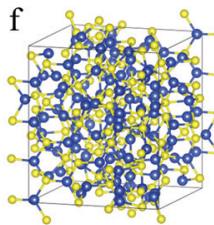

c

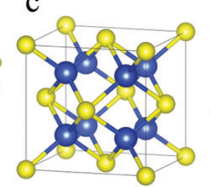

d

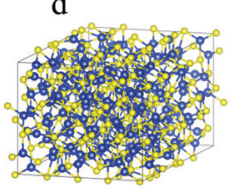

$\mathrm{g}$

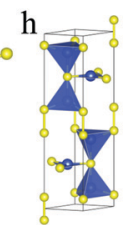

Fig. 1 Crystal structures for (a) low chalcocite, (b) high chalcocite, (c) cubic chalcocite, (d) djurleite, (e) digenite, (f) roxbyite (g) anilite, and (h) covellite phases. Blue and yellow spheres represent copper and sulfur atoms, respectively. Schematics were generated using VESTA.

covellite CuS has been demonstrated to be intrinsically metallic rather than being a heavily doped semiconductor. The S-S covalent bonding and $\mathrm{S}$ hypervalency $\left(\mathrm{S}_{2}{ }^{2-}\right.$ and $\left.\mathrm{S}^{2-}\right)$ generates two free holes which are almost equally distributed among the six layers per unit cell $\left(\mathrm{Cu}_{6} \mathrm{~S}_{6}\right)$, leading to metallic character with hole density up to $\sim 10^{22} \mathrm{~cm}^{-3} \cdot 58,59$

\subsection{Generation of holes in $\mathrm{Cu}_{2} \mathrm{~S}$ valence band}

In copper sulfides, the top of valence band is essentially contributed from the sulfur $3 p$ orbitals, and the bottom of the conduction band is mainly contributed from the copper $4 \mathrm{~s}$ orbitals. ${ }^{24}$ It is assumed that each copper atom provides one 4 s electron to bonding, while each sulfur atom provides six electrons. In the fully stoichiometric $\mathrm{Cu}_{2} \mathrm{~S}$, the valence band is completely filled and the materials would perform as intrinsic semiconductor. The copper cations in the lattice have a valence of +1 , and the sulfur anions have a valence of -2 . Even though the low chalcocite phase is the most stable one among the three chalcocite phases, it is prone to generate $\mathrm{Cu}$ vacancies. When the $\mathrm{Cu}_{2} \mathrm{~S}$ NPs are exposed to oxidative environment, electrons are extracted along with $\mathrm{Cu}^{+}$in order to keep electrostatic neutrality, and therefore copper vacancies (holes) are generated in the top of the valence band (Fig. 2a) ${ }^{60}$ This hole generation mainly affects the valence of sulfur anion framework since the valence band has a major contribution from sulfur $3 p$ orbitals, whereas the valence of copper cation inside the NP lattice keeps close to $+1 .{ }^{24}$ For example, $\mathrm{Cu}^{+}+($copper $4 \mathrm{~s}) \mathrm{e}^{-}+1 / 2 \mathrm{O}_{2}=\mathrm{CuO}$, i.e., $\mathrm{Cu}^{+}+1 / 2 \mathrm{O}_{2}=\mathrm{CuO}-($ copper $4 \mathrm{~s}) \mathrm{e}^{-}$, indicates a lack of one bonding electron in sulfur $3 p$ orbital. Since the sulfur $3 p$ orbitals contribute to the valence band, an extraction of $\mathrm{Cu}^{+}$ results in a lack of one bonding electron $\left(\mathrm{h}^{+}\right)$in sulfur $3 \mathrm{p}$ orbital, that is, produce one hole in valence band. In order to better understand the optical properties of $\mathrm{Cu}_{2-x} \mathrm{~S}$, it is beneficial to recall some basic aspects of the band structure. The optical bandgap for hole doped $\mathrm{Cu}_{2-x} \mathrm{~S}$ is defined as the energy difference between the bottom of the conduction band and the highest occupied valence band. The optical bandgap is hole concentration dependent and it is larger than that of undoped $\mathrm{Cu}_{2} \mathrm{~S}$. This optical bandgap variation by hole doping in valence a

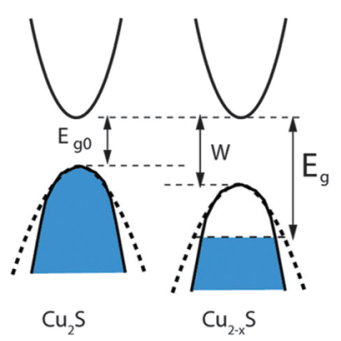

$\mathrm{b}$

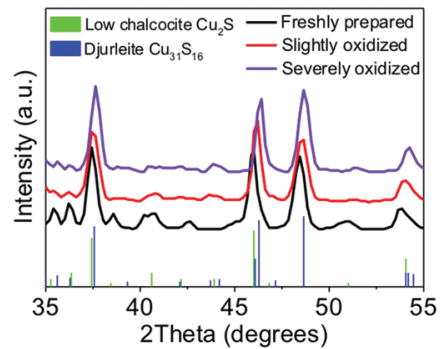

Fig. 2 (a) Band structures of $\mathrm{Cu}_{2} \mathrm{~S}$ and $\mathrm{Cu}_{2-x} \mathrm{~S}$. In $\mathrm{Cu}_{2-x} \mathrm{~S}$, both of the intrinsic $\left(E_{\mathrm{go}}\right)$ and optical bandgaps $\left(E_{\mathrm{g}}\right)$ increased with hole generation. (Reproduced with permission from ref. 60, copyright 2014 Royal Society of Chemistry.) (b) Crystal structure transformation from low chalcocite $\mathrm{Cu}_{2} \mathrm{~S}$ to djurleite $\mathrm{Cu}_{31} \mathrm{~S}_{16}\left(\mathrm{Cu}_{1.94} \mathrm{~S}\right)$ triggered by air oxidation. In spite of very similar XRD patterns, the shift of XRD peaks to higher diffraction angles indicates the removal of copper atoms and leads to the crystal structure transformation. (Reproduced with permission from ref. 62, copyright 2018 American Chemical Society.)

band is called the Burstein-Moss effect, which has been well exploited in copper chalcogenide NPs. ${ }^{11,20}$ In addition to the Burstein-Moss effect in $\mathrm{Cu}_{2} \mathrm{~S}$, another important point to address is the intrinsic instability, which is derived from its thermodynamic propensity toward a copper deficiency because of the low chemical potential of $\mathrm{Cu}^{0} .{ }^{61}$ Previous experimental investigations have found that $\mathrm{Cu}_{2} \mathrm{~S}$ is unstable at ambient conditions and rapidly transforms into hole doped $\mathrm{Cu}_{2-x} \mathrm{~S}$ phases by air oxidation, most probably djurleite $\mathrm{Cu}_{1.94} \mathrm{~S}$, which has been thermodynamically stable under ambient conditions (Fig. 2b). ${ }^{62}$ Owing to the lower crystallographic symmetry and thus lower free energy than low chalcocite $\mathrm{Cu}_{2} \mathrm{~S}$, djurleite is more stable in bulk and in NPs. ${ }^{19,63,64}$

\subsection{Optical modeling}

The origins of LSPR in hole-doped $\mathrm{Cu}_{2-x} \mathrm{~S}$ NPs remain poorly understood. In order to better understand their LSPR, it is useful to introduce some general concepts with regard to optical responses in noble metals. We select the most prominent theory Drude model to reproduce and predict some of the optical responses of $\mathrm{Cu}_{2-x} \mathrm{~S}$, and it is described by the following complex dielectric function:

$$
\varepsilon(\omega)=\varepsilon_{1}(\omega)+\mathrm{i} \varepsilon_{2}(\omega)
$$

where

$$
\varepsilon_{1}=\varepsilon_{\infty}-\omega_{\mathrm{p}}^{2} /\left(\omega^{2}+\Gamma^{2}\right)
$$

and

$$
\varepsilon_{2}=\omega_{\mathrm{p}}^{2} \Gamma /\left[\omega\left(\omega^{2}+\Gamma^{2}\right)\right]
$$

are the real and imaginary part of the dielectric function, respectively. The density of free holes in $\mathrm{Cu}_{2-x} \mathrm{~S}$ should be large enough to achieve a negative value of $\varepsilon_{1}$ to support LSPR. In addition, the smaller value of $\varepsilon_{2}$ is demanded for better plasmonic performances or applications. ${ }^{60,65}$ The free carrier damping constant $\Gamma$ depicts the damping caused by the scattering 
with electrons, phonons, lattice defects or impurities during collective oscillations. ${ }^{24} \varepsilon_{\infty}$ is the high frequency dielectric constant and $\omega$ is the frequency of incident light. The relationship between bulk plasma frequency $\omega_{\mathrm{p}}$ and free carrier density $N$ is shown in the following equation:

$$
\omega_{\mathrm{p}}^{2}=\left(N e^{2}\right) /\left(\varepsilon_{0} m^{*}\right)
$$

where $m^{*}$ is the effective mass of free carrier, $\varepsilon_{0}$ is the vacuum dielectric permittivity and $e$ is elementary charge. ${ }^{24}$ As shown in eqn (4), the plasma frequency $\omega_{\mathrm{p}}$ directly correlates with the carrier density $N$, providing a tool to estimate the carrier density of a specific sample. This indicates that an increase in carrier density gives rise to an increase of the $\omega_{\mathrm{p}}$ and a blue-shift of the LSPR peak. In the case of $\mathrm{Cu}_{2-x} \mathrm{~S}$, the dominate morphology is the ND. In the electro-static limit, where the NP diameter is much smaller than the wavelength $(d \ll \lambda)$, the dipole polarizability $(\alpha)$ of a ND can be approximated employing basic scattering theory for an oblate spheroid with semi-axis $a<b=c .^{32}$ To calculate the hole density $N_{\mathrm{h}}$ of $\mathrm{Cu}_{2-x} \mathrm{~S}$ NDs, the $\alpha$ can be expressed as:

$$
\alpha_{j}=\left[3 \varepsilon_{0} V\left(\varepsilon_{j}-\varepsilon_{\mathrm{m}}\right)\right] /\left[3 \varepsilon_{\mathrm{m}}+3 L_{j}\left(\varepsilon_{j}-\varepsilon_{\mathrm{m}}\right)\right]
$$

where $j=1,2$, or $3, V$ is spheroid volume, $L_{j}$ is a morphologydependent constant calculated from the ratio of axes of the oblate spheroid with $L_{1}+L_{2}+L_{3}=1$ and $L_{2}=L_{3}$. In a resonance condition, the denominator in eqn (5) must be zero:

$$
3 \varepsilon_{\mathrm{m}}+3 L_{j}\left(\varepsilon_{j}-\varepsilon_{\mathrm{m}}\right)=0, \quad \varepsilon_{1, j}=\left\{-\left[\left(1-L_{j}\right)\right] / L_{j}\right\} \varepsilon_{\mathrm{m}}
$$

where $\varepsilon_{1, j}$ is the real part of dielectric function $\left(\varepsilon_{j}\right)$ of the $\mathrm{Cu}_{2-x} \mathrm{~S}$, $\varepsilon_{\mathrm{m}}$ is dielectric constant of the surrounding medium. In eqn (2), the term $\Gamma$ can be calculated from absorption spectrum shown in the following equation:

$$
\Gamma=c\left(\lambda_{1 / 2}\right) /\left(\lambda_{\max }^{2}\right)
$$

where $c$ is the speed of light, $\lambda_{1 / 2}$ is the full width at halfmaximum (FWHM) of the LSPR peak and $\lambda_{\text {max }}$ is the absorption maximum wavelength. It is worth noting that, because of the non-parabolicity of the valence band in $\mathrm{Cu}_{2-} \mathrm{S}$, the effective mass of hole is highly dependent on the hole density, suggesting that one cannot extract the hole density directly from eqn (4). Occasionally, the hole density can be estimated applying eqn (4) to the LSPR of $\mathrm{Cu}_{2-x} \mathrm{~S}$ NDs with several different crystal structures, taking the different effective hole masses of the various $\mathrm{Cu}_{2-x} \mathrm{~S}$ structures into consideration. ${ }^{43,66,67}$ Furthermore, Kriegel et al. reported that the Drude model cannot sufficiently describe the experimental absorption spectrum of $\mathrm{Cu}_{2-x} \mathrm{~S}$ NPs directed by copper vacancies. The holes in the valence band of $\mathrm{Cu}_{2-x} \mathrm{~S}$ results in a deviation from the purely metallic behavior, meaning that such holes cannot be treated as fully free particles and that the effects of hole localization are important. ${ }^{35}$ However, as aforementioned, the covellite CuS with highest hole density represents a special case. In an exhaustive work, Xie et al. investigated CuS NDs with different sizes using the discrete dipole approximation method performed within the framework of Drude-Sommerfeld model to demonstrate their morphology and size dependent LSPR. $^{68}$ The experimental spectra of several CuS NDs of various sizes were satisfactorily reproduced by extracting the Drude parameters, indicating that the LSPR responses of CuS are consistent with the predictions by the Drude model and the holes in this crystal structure can be treated as fully free. Such treatment is likely owing to the fact that the carriers in CuS derive from the inherent metallic-like character resulting from the significant density of lattice-constitutional valence band free holes, which is quite different from the other copper sulfide structures.

\subsection{Flexible LSPR manipulation of $\mathrm{Cu}_{2-x} \mathrm{~S}$ NPS}

Except for $\mathrm{Cu}_{2} \mathrm{~S}$, all the copper-deficient $\mathrm{Cu}_{2-x} \mathrm{~S}$ phases are in LSPR-active state. Besides the well-known size effect, the LSPR of $\mathrm{Cu}_{2-x} \mathrm{~S}$ NPs can be flexibly manipulated by several means including hole density tuning, structural control and transformation as well as morphology control according to the above optical modeling. Particularly, hole density tuning is realized through chemical redox reactions, crystal structure transformation is triggered by removal/insertion of $\mathrm{Cu}^{+}$and by sulfur sources, and morphology control is directed by metal ions and copper/ sulfur precursor reactivity.

2.4.1 Hole density tuning via chemical redox reactions. According to eqn (2)-(4) in Section 2.3, it is believed that even a minor variation of hole density in $\mathrm{Cu}_{2-x} \mathrm{~S}$ NPs can result in strong effect on spectral position and intensity of the LSPR. Therefore, it allows for a controllable LSPR tuning over a wide spectral range through chemical redox reactions by oxidizing/reducing agents. Oxidizing agent such as air $\left(\mathrm{O}_{2}\right)$, iodine $\left(\mathrm{I}_{2}\right)$, alkylamines as well as cerium(Iv) ammonium nitrate $\left[\left(\mathrm{NH}_{4}\right)_{2} \mathrm{Ce}\left(\mathrm{NO}_{3}\right)_{6}\right]$ can induce a generation of copper vacancies in the valence band of $\mathrm{Cu}_{2-x} \mathrm{~S}$, leading to an increase of hole density. ${ }^{20,61,69,70}$ As a consequence of oxidation, evolved LSPR band, gradually blue-shifted LSPR peak, increscent peak intensity and decrescent peak width were observed (Fig. 3a). In contrast, reducing agent such as alkylthiols, 3-mercaptopropionic acid (MPA), sodium biphenyl as well as diisobutylaluminium hydride (DIBAH) can induce a filling of copper vacancies, leading to a decrease of hole density. ${ }^{11,61,62,69}$ As a consequence of reduction, suppressed LSPR band, gradually red-shifted LSPR peak, decrescent peak intensity and increscent peak width were observed (Fig. 3b). The presence of oxidants such as oxygen favors the extraction of $\mathrm{Cu}^{+}$ from the $\mathrm{Cu}_{1.8} \mathrm{~S}$ ND lattice through the formation of $\mathrm{CuO}$ (hole generation), while the electron donors such as MPA favors electron injection into the ND lattice and thus the filling of holes (Fig. 3c). It is worth noting that, upon oxidation and reduction, the accompanied optical bandgap also blue-shifts and red-shifts, known as Burstein-Moss effect, which is expected from a change of hole density within the ND. The estimated hole density varied from $N_{\mathrm{h} 1}=4.47 \times 10^{21} \mathrm{~cm}^{-3}$ to $N_{\mathrm{h} 2}=5.88 \times 10^{21} \mathrm{~cm}^{-3}$ upon oxidation, while the hole density decreased to $N_{\mathrm{h} 3}=5.20 \times$ $10^{21} \mathrm{~cm}^{-3}$ after MPA reduction. In spite of the variation of LSPR and optical bandgap, the crystal structure of roxbyite is remained.

2.4.2 Crystal structure control and transformation. In addition to hole density, LSPR manipulation can be realized by crystal structure control and transformation. The capability 
a

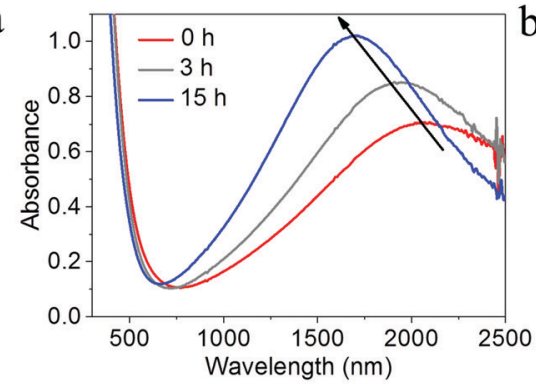

$\mathrm{c}$

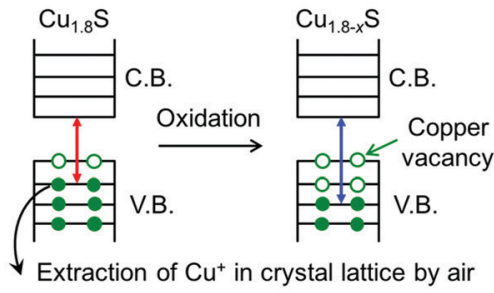

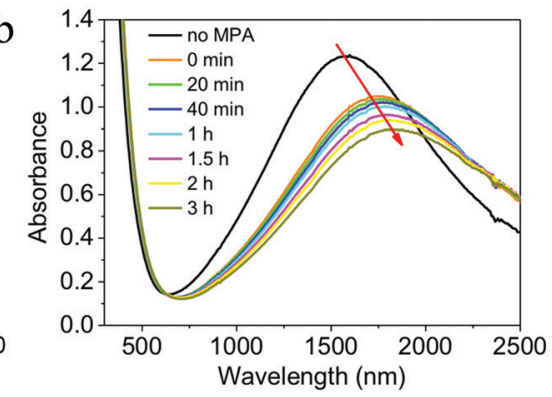

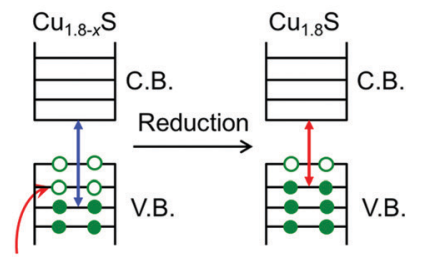

Filling of holes in crystal lattice by MPA

Fig. 3 Chemical redox reactions of roxbyite $\mathrm{Cu}_{1.8} \mathrm{~S}$ NDs. Time evolution of UV-vis-NIR absorption spectra of $\mathrm{Cu}_{1.8} \mathrm{~S} N D s$ under (a) air oxidation and (b) MPA reduction. (c) Scheme of oxidation induced copper vacancy generation and reduction induced hole filling. Note: $\mathrm{Cu}_{1.8-x} \mathrm{~S}$ suggests the copperpoor roxbyite phase. Chemical redox reactions change the hole desnity or the stoichiometry of roxbyite copper sulfide, but do not change the crystal structure. (Reproduced with permission from ref. 69, copyright 2020 Springer.)

to access different crystal structures from a given NP holds great potential for fundamental studies and diverse applications. The crystal structure control has been realized by different $\mathrm{Cu} / \mathrm{S}$ feed ratios and sulfur sources. ${ }^{21-23}$ For crystal structure transformation, started from covellite $\mathrm{CuS}$, via either $\mathrm{Cu}^{+}$insertion or alkylthiol thermal-treatment, a series of $\mathrm{Cu}_{2-x} \mathrm{~S}$ phases can be achieved. ${ }^{71,72}$ Actually, the most important factor among $\mathrm{Cu}_{2-x} \mathrm{~S}$ with different crystal structures on the LSPR is the hole density, ${ }^{33}$ because the well-studied crystal structures such as low/high chalcocite, djurleite, roxbyite and covellite are catalogued by asymmetric hcp of sulfur anions, with copper cations taking up interstitial spaces between the sulfur lattices. As aforementioned, according to eqn (2)-(4) in Section 2.3, crystal structure control and transformation will result in a variation of hole density, leading to much stronger effect on the LSPR peak position and absorption strength. In the case of crystal structure transformation, upon an addition of $\mathrm{Cu}(\mathrm{I})$ complex, terakis (acetonitrile) copper(I) hexafluorophosphate $\left(\left[\mathrm{Cu}-\left(\mathrm{CH}_{3} \mathrm{CN}\right)_{4}\right] \mathrm{PF}_{6}\right)$, covellite $\mathrm{Cu}_{1.1} \mathrm{~S}$ NDs were successively enriched with copper and converted into $\mathrm{Cu}_{1.3} \mathrm{~S}, \mathrm{Cu}_{1.5} \mathrm{~S}$ and $\mathrm{Cu}_{2} \mathrm{~S}$, respectively (Fig. $4 \mathrm{a}$ ). $\mathrm{Cu}_{1.3} \mathrm{~S}$ and $\mathrm{Cu}_{1.5} \mathrm{~S}$ could be assigned to metastable "copper-rich covellite" phase, evidenced by a slight shift of XRD peaks of covellite to lower diffraction angles. The $\mathrm{Cu}_{2} \mathrm{~S}$ could not be assigned considering just a single phase, and might be a mixture of anilite $\mathrm{Cu}_{1.75} \mathrm{~S}$ and low chalcocite $\mathrm{Cu}_{2} \mathrm{~S}$. Combined $\mathrm{X}$-ray photoelectron spectroscopy (XPS) and electron paramagnetic resonance (EPR) data indicate that, during this transformation the valence of copper cation keeps close to +1 , compensated by the variation of sulfur anion valence from -1 in $\mathrm{CuS}$ to -2 in $\mathrm{Cu}_{2} \mathrm{~S}$. Along with structural change, a suppression and even a quenching of LSPR band of covellite $\mathrm{Cu}_{1.1} \mathrm{~S}$ was also observed (Fig. $4 \mathrm{~b}$ ). This tendency of LSPR variation is similar with that by chemical reduction, but has much stronger effect. Accordingly, crystal structure transformation with large tuning of hole density, a

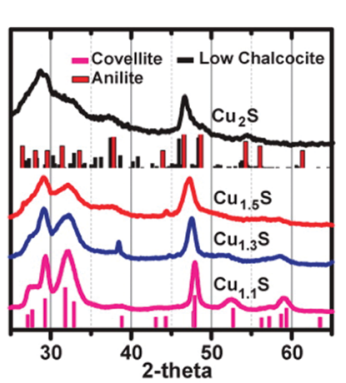

$\mathrm{c}$
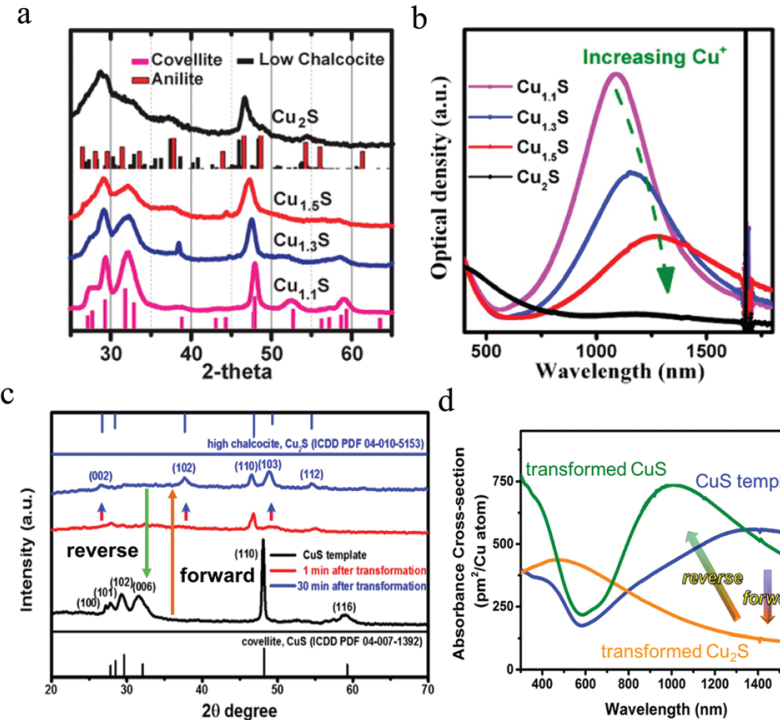

d

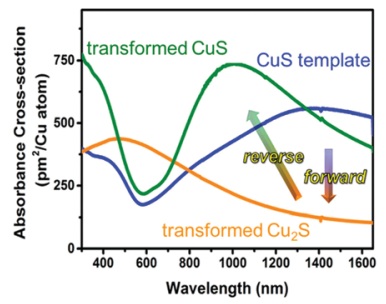

Fig. 4 Crystal structure transformation of covellite copper sulfide NDs. (a) $\mathrm{Cu}^{+}$complex reduction induced and (c) 1-DDT thermal-reduction induced structural change and ( $b$ and d) corresponding UV-vis-NIR absorption spectra evolution. In (c), the transformation from $\mathrm{Cu}_{2} \mathrm{~S}$ to $\mathrm{CuS}$ was triggered by sulfurorganic solutions including sulfur-oleic acid, sulfur-oleylamine and sulfuroctadecene. (a) (Reproduced with permission from ref. 71, copyright 2013 American Chemical Society.) and (b) (Reproduced with permission from ref. 72, copyright 2017 American Chemical Society.)

provides a favorable tool to manipulate LSPR response for special applications. Furthermore, not only the $\mathrm{Cu}(\mathrm{I})$ complex, but also alkylthiol such as 1-dodecanethiol (1-DDT) could induce structural transformation of covellite $\mathrm{CuS}$ to chalcocite $\mathrm{Cu}_{2} \mathrm{~S}$. Upon thermal-treatment, 1-DDT molecules broke disulfide bonds in $\mathrm{CuS}$ and removed sulfur from the lattice, which drives an expansion of lattice in high chalcocite $\mathrm{Cu}_{2} \mathrm{~S}$ along the $c$-axis 
direction (Fig. 4c). Subsequently, the transformed $\mathrm{Cu}_{2} \mathrm{~S}$ was recovered to $\mathrm{CuS}$ by sulfur-organic solutions. Interestingly, a morphology as well as a particle size variation is accompanied with the forward and reverse structural change. Excluding the effect of morphology and size variation, the LSPR response is almost quenched by phase transformation from $\mathrm{CuS}$ to $\mathrm{Cu}_{2} \mathrm{~S}$, and partially recovered by the reverse phase transformation from $\mathrm{Cu}_{2} \mathrm{~S}$ to $\mathrm{CuS}$ (Fig. $4 \mathrm{~d}$ ).

2.4.3 Morphology control. In metals, plasmon oscillation mode and thus the number of LSPR peak is mainly determined by NP morphology. Control of NP morphology provides a powerful tool to tune their LSPR responses. For example, anisotropic silver nanorods (NRs) and triangular nanoplates possess multiple LSPR peaks, while Ag nanospheres (NSs) have only LSPR peak. ${ }^{73-75}$ Nonetheless, in the case of $\mathrm{Cu}_{2-x} \mathrm{~S}$ NPs, the effect of morphology on the LSPR is not clearly understood and it seems that the morphology has little influence on their plasmon oscillation mode. Djurleite $\mathrm{Cu}_{1.94} \mathrm{~S}$ tetradecahedral NPs prepared by $\mathrm{Sn}^{4+}$ directed seeding growth of NDs only exhibit one LSPR peak in spite of anisotropic morphology. Heating these NPs in the presence of oleylamine results in pseudomorphic structural conversion to roxbyite $\mathrm{Cu}_{1.8} \mathrm{~S}$, which merely increases the plasmon oscillation strength rather than the oscillation mode (Fig. 5a). ${ }^{76}$ Moreover, djurleite $\mathrm{Cu}_{1.94} \mathrm{~S}$ NRs were prepared by selective utilization of copper precursors. In contrast to silver NRs with two oscillation modes, i.e., transversal mode (T-mode) and longitudinal mode (L-mode), the $\mathrm{Cu}_{1.94} \mathrm{~S}$ NRs only show one LSPR peak and an oxidation of the NRs by $\mathrm{Ce}^{4+}$ ammonium nitrate could not induce the anisotropic oscillation mode (Fig. 5b). Furthermore, not only the NRs, but also the hexagonal NDs as well as prisms does not show any morphology related plasmon oscillation mode. ${ }^{77}$ As aforementioned, according to eqn (2) and (4)-(7) in Section 2.3, the hole density for the singular LSPR peak in the ND can be determined. In the case of $\mathrm{Cu}_{2-x} \mathrm{~S}$ NR with semi-axis $a>b=c$, the determination of hole density is similar with that of $\mathrm{Cu}_{2-x} \mathrm{~S}$ ND. $L_{j}$ for rod is also a morphology-dependent constant calculated from the ratio of axes of the prolate spheroid with $L_{1}+L_{2}+L_{3}=1$ and $L_{2}=L_{3}$. The value of $L_{1}$ is dependent on the ratio of $(b / a)$ and if $L_{1}=0$ and $L_{2}=L_{3}=$ 0.500 , the morphology is rod. ${ }^{32}$ However, different from above reports, contradicting reports on the effect of morphology on the
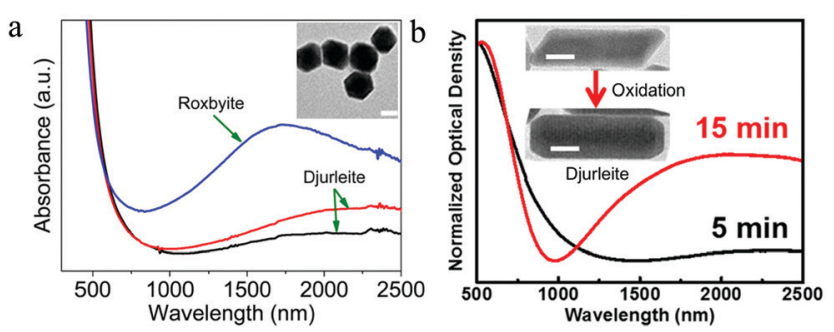

Fig. 5 UV-vis-NIR absorption spectra of (a) roxbyite $\mathrm{Cu}_{1.8} \mathrm{~S}$ and djurleite $\mathrm{Cu}_{1.94} \mathrm{~S}$ tetradecahedral NPs, (Reproduced with permission from ref. 76, copyright 2016 American Chemical Society.) and (b) Djurleite $\mathrm{Cu}_{1.94} \mathrm{~S}$ NRs. Scale bar in (a) and (b) is $20 \mathrm{~nm}$. (Reproduced with permission from ref. 77 , copyright 2017 American Chemical Society.)
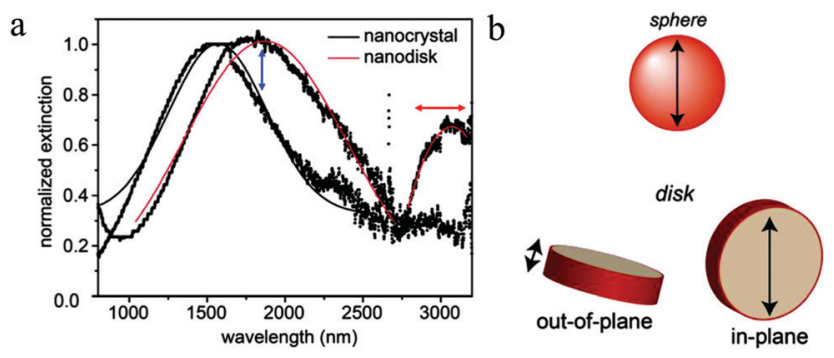

Fig. 6 (a) NIR and MIR absorption spectra and (b) scheme of LSPR polarizations for $\mathrm{Cu}_{2-x} \mathrm{~S}$ NSs and NDs. The LSPR energy, line shape and relative oscillation intensities of the two plasmon bands can be tuned by varying the aspect ratio or free hole density of the ND. (Reproduced with permission from ref. 32, copyright 2011 American Chemical Society.)

plasmon oscillation mode of $\mathrm{Cu}_{2-x} \mathrm{~S}$ NPs has been published. Hsu et al. prepared chalcocite/djurleite $\mathrm{Cu}_{2-x} \mathrm{~S}$ NSs and NDs using a solventless synthesis and the NSs show one dipolar oscillation mode, while for NDs, the oscillation splits into a higher energy (1600-1900 nm) out-of-plane mode and a low energy (3000-3100 nm) in-plane mode (Fig. 6a and b). ${ }^{32}$ In contrast, metallic covellite CuS NDs only show an in-plane oscillation mode. ${ }^{33,71}$ Therefore, it is highlighted to consider the crystal structure alongside NP morphology to avoid confusion in assigning LSPR peaks to corresponding oscillation modes.

\subsection{Surface chemistry and LSPR in $\mathrm{Cu}_{2-x} \mathrm{~S}$}

As aforesaid, the free hole density and thus the LSPR in $\mathrm{Cu}_{2-x} \mathrm{~S}$ NPs can change spontaneously under exposure of redox environments. Controllable surface hole density in $\mathrm{Cu}_{2-x} \mathrm{~S}$ is essential to any application which requires constant plasmonic behavior, including solar energy conversion, sensing, or phototherapy. Nevertheless, the relationship between surface chemistry and LSPR evolution/stabilization in $\mathrm{Cu}_{2-x} \mathrm{~S}$ has been less investigated. Wei et al. reported the effect of oxygen exposure on the variation of LSPR in most stable covellite CuS NDs. ${ }^{78}$ Oxygen molecules adsorbed on the ND surface induced a blue-shift of LSPR peak in the sample and it could be reverted by the repassivation of organic surfactant, oleylamine (Fig. 7a). This surface chemistry relevant LSPR is explained by the fact that, the adsorbed oxygen molecules acted as an electron acceptor, which withdraws electrons from the CuS ND, resulting in an increase of hole density. Furthermore, how different organic surfactants affecting the absorption spectra of CuS NDs was investigated. In spite of approximately the same refractive index, the different electron withdrawing abilities of the surfactant in terms of Lewis acids and bases is responsible for the shift of LSPRs. ${ }^{78}$ Therefore, it is highly important to stabilize the LSPR absorption profile when making use of the $\mathrm{Cu}_{2-x} \mathrm{~S}$ for special applications. Manna et al. prepared CuS@amorphous $\mathrm{CuPd}_{x} \mathrm{~S}$ heterostructure to tune and lock the LSPR in covellite CuS NDs. ${ }^{79}$ This core@shell structure was obtained by reacting the as-synthesized CuS NDs with $\mathrm{Pd}^{2+}$ in the presence of a reducing agent ascorbic acid. The reorganization of the CuS lattice caused by preferential accommodation of $\mathrm{Pd}$ atoms between the bilayer formed by the S-S covalent bonds, led to the formation of protective amorphous $\mathrm{CuPd}_{x} \mathrm{~S}$ layer. $^{79}$ 


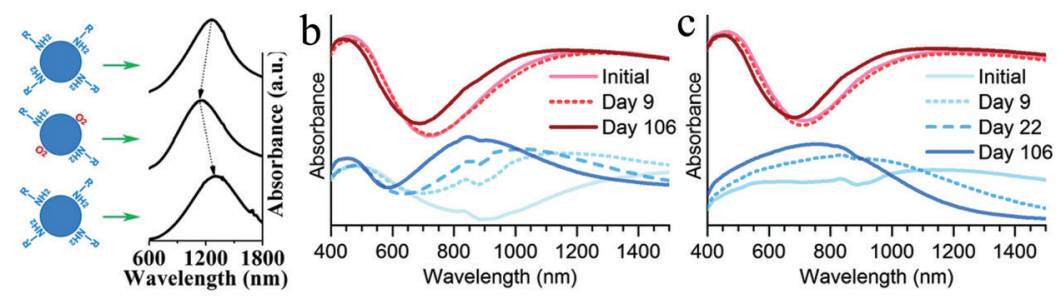

$\mathrm{d}$
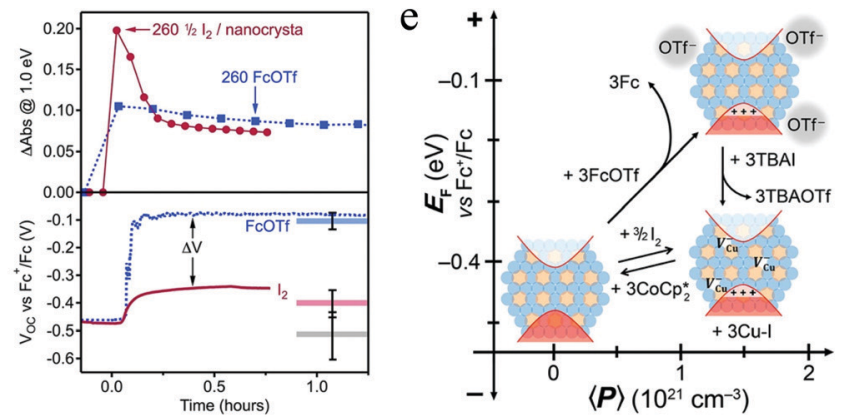

Fig. 7 (a) Scheme of the process of LSPR shifts in CuS NDs with unload and reload of organic surfactant oleylamine. (Reproduced with permission from ref. 78, copyright 2013 American Chemical Society.) Time evolution of LSPR absorption spectra of (b) monoclinic and (c) tetragonal chalcocite NPs with (red, top) and without (blue, bottom) $\mathrm{MoS}_{4}{ }^{2-}$-treatment. The LSPR absorption in the initial samples indicates that the chalcocite NPs have been oxidized after purification. (Reproduced with permission from ref. 81, copyright 2016 Royal Society of Chemistry.) (d) Differential LSPR absorption intensity and open-circuit potentials $\left(V_{O C}\right)$ plotted vs. time for $\mathrm{Cu}_{2} \mathrm{~S} N$ Ps oxidized with same equivalent of $1 / 2 \mathrm{I}_{2}$ (solid) and FcOTf (dashed). (e) Summary of redox control over hole density, copper vacancy concentration, and $E_{\mathrm{F}}$ in $\mathrm{Cu}_{2-x} \mathrm{~S} N \mathrm{NS}$. (Reproduced with permission from ref. 83, copyright 2018 American Chemical Society.)

In the case of $\mathrm{Cu}_{2} \mathrm{~S} \mathrm{NPs}$, the loss of copper is a surface-facilitated process. ${ }^{11}$ Organic surfactants such as 1-dodecanethiol, which is widely used in the synthesis of $\mathrm{Cu}_{2} \mathrm{~S}$ NPs, as well as commonly employed oleylamine cannot protect the sample from oxidation sufficiently and results in a rapid evolution of LSPR absorption bands. ${ }^{19,80}$ Spontaneous hole generation has limited the use of chalcocite copper sulfides as a solar light absorber in photovoltaics. In order to passivate the chalcocite $\mathrm{Cu}_{2-x} \mathrm{~S}$ NPs, Plass et al. chose tetrathiomolybdate $\left(\mathrm{MoS}_{4}{ }^{2-}\right)$ as an effective replacement surfactant due to its strong chelation to copper cations, which could form an inert layer where oxidation could not occur and prevented $\mathrm{Cu}^{+}$loss from the sample. ${ }^{81}\left(\mathrm{NH}_{4}\right)_{2} \mathrm{MoS}_{4}$-treated $\mathrm{Cu}_{2-x} \mathrm{~S}$ NPs were stable, preventing evolution in the LSPR absorption in air (Fig. 7b and c) and other oxidative environments. Notably, the LSPR stabilization by $\left(\mathrm{NH}_{4}\right)_{2} \mathrm{MoS}_{4}$ treatment is a concentration dependent process. An increase of the $\left(\mathrm{NH}_{4}\right)_{2} \mathrm{MoS}_{4}$ concentration results in the dissolution of $\mathrm{Cu}_{2-x} \mathrm{~S}$ NPs and the reformation of amorphous $\mathrm{Cu}_{2} \mathrm{MoS}_{4}{ }^{81}$ In addition to the surface passivation by inorganic surfactant, the chalcocite $\mathrm{Cu}_{2-x} \mathrm{~S}$ can be stabilized by alloying with metal cations such as $\mathrm{Ag}^{+}$and $\mathrm{Fe}^{3+36,82}$ Another important phenomenon of surface chemistry and LSPR in $\mathrm{Cu}_{2-x} \mathrm{~S}$ NPs is the stabilization of excess free holes. Gamelin et al. applied spectroelectrochemical potentiometry as a quantitative in situ technique to probe the low chalcocite $\mathrm{Cu}_{2} \mathrm{~S}$ NP Fermi-level energies $\left(E_{\mathrm{F}}\right)$ during redox reactions. They investigated spectroscopically indistinguishable LSPR bands in $\mathrm{Cu}_{2} \mathrm{~S}$ NPs with and without generation of lattice copper vacancies and demonstrated that the copper vacancies are more effective in the stabilization of excess free holes than surface anions. ${ }^{83}$ With the injection of same equivalent of oxidant (ferrocenium triflate: FcOTf or $1 / 2 \mathrm{I}_{2}$ ), the LSPR absorption of $\mathrm{Cu}_{2} \mathrm{~S}$ NPs rapidly increases and then slowly drops over several minutes to converge to an equilibrium value. The more positive equilibrium potential $\left(V_{\text {eq }}\right)$ when NPs oxidized by FcOTf than by $\mathrm{I}_{2}$, meaning that the holes formed in valence-band by FcOTf oxidation are nearly $300 \mathrm{mV}$ less stable than those formed by $\mathrm{I}_{2}$ oxidation at the same hole density $\langle\mathrm{P}\rangle$ (Fig. 7d). This difference indicates that these two oxidants yield substantially different p-doped NPs. The $\mathrm{Cu}-\mathrm{I}$ bond formation could induce and stabilize the holes in valence band and provide the necessary driving force to induce copper vacancy formation. Furthermore, the oxidized $\mathrm{Cu}_{2-x} \mathrm{~S}$ NPs by $\mathrm{I}_{2}$ were reduced by the addition of decamethylcobaltocene $\left(\mathrm{CoCp}^{*}{ }_{2}\right)$. The $\mathrm{CoCp}_{2}{ }_{2}$ both eliminated valence band holes and pushed the $\mathrm{Cu}^{+}$back into the $\mathrm{Cu}_{2-x} \mathrm{~S}$ NP lattice to reform the stoichiometric $\mathrm{Cu}_{2} \mathrm{~S}$ phase (Fig. 7e). ${ }^{83}$

\subsection{Correlation between LSPR and photoluminescence in $\mathrm{Cu}_{2-x} \mathrm{~S}$}

The investigation on exciton-plasmon coupling is highly interesting for the exploration of photocatalytic charge transfer, emission enhancement or suppression as well as the Fano resonances. ${ }^{24}$ For $\mathrm{Cu}_{2-x} \mathrm{~S}$ with dually excitonic and plasmonic responses, the photoluminescence (PL) is highly correlated with its LSPR. Kriegel et al. monitored the PL of $\mathrm{Cu}_{2-x} \mathrm{~S}$ NPs as a function of hole density, which is dynamically tuned by air oxidation and DIBAH reduction (Fig. 8a and b). ${ }^{11}$ As expected, a suppression and even a quenching of PL intensity was observed upon oxidation as the number of copper vacancy increased, which leads to more efficient in non-radiative recombination of excitons. The quenching of PL could be attributed to several 
a

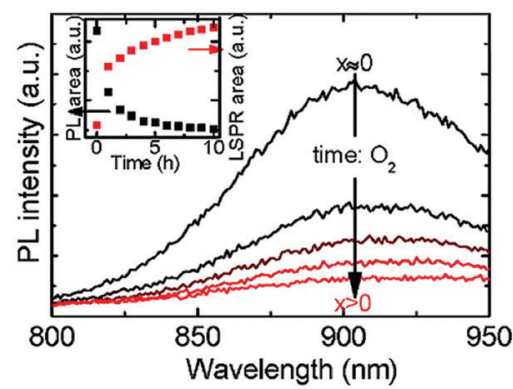

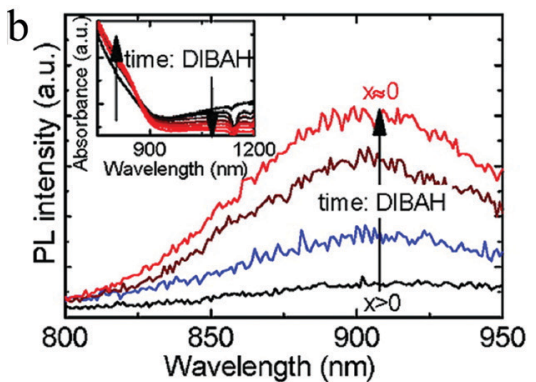

$\mathrm{c}$

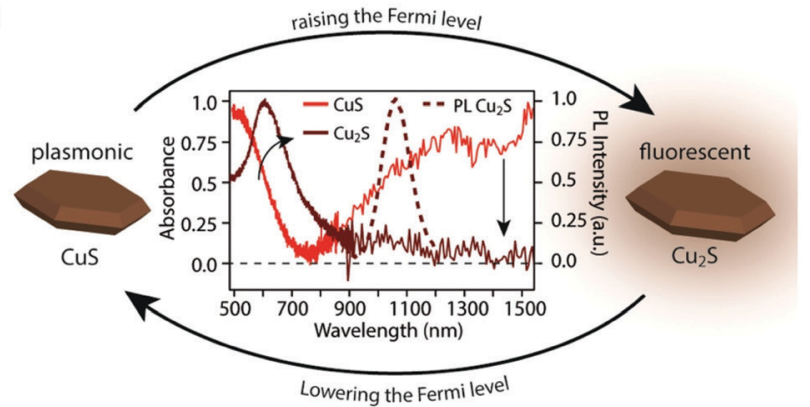

Fig. 8 Time evolution of the PL spectra of $\mathrm{Cu}_{2-x} \mathrm{~S} \mathrm{NPs} \mathrm{(a)} \mathrm{during} \mathrm{oxidation} \mathrm{by} \mathrm{air} \mathrm{and} \mathrm{(b)} \mathrm{subsequent} \mathrm{reduction} \mathrm{by} \mathrm{DIBAH.} \mathrm{PL} \mathrm{intensity} \mathrm{conversely} \mathrm{varied}$ with the density of copper vacancy. (Reproduced with permission from ref. 11, copyright 2012 American Chemical Society.) (c) Crystal structure transformation from plasmonic covellite CuS to fluorescent low chalcocite $\mathrm{Cu}_{2} \mathrm{~S}$ by electrochemical intercalation of $\mathrm{Cu}^{+}$. The PL of the $\mathrm{Cu}_{2} \mathrm{~S} N \mathrm{NP}$ film centered around $1050 \mathrm{~nm}$ and the quantum yield was established to be ca. 1.8\%. (Reproduced with permission from ref. 85, copyright 2017 American Chemical Society.)

processes such as Auger recombination, carrier trapping as well as exciton-plasmon energy transfer. ${ }^{11,84}$ Conversely, PL intensity was gradually recovered upon reduction, owing to a decrease of copper vacancy. Furthermore, time-resolved PL spectroscopy indicates that the exciton lifetime is shortened with the emergence of LSPR, while it is lengthened with the LSPR bleaching. In addition, electrochemical intercalation of $\mathrm{Cu}^{+}$into plasmonic CuS NP film resulted in an irreversible phase conversion to the fluorescent $\mathrm{Cu}_{2} \mathrm{~S}$ (Fig. 8c). ${ }^{85}$ As aforesaid, the as-synthesized low chalcocite $\mathrm{Cu}_{2} \mathrm{~S}$ NPs are usually unstable under ambient conditions and transform easily to djurleite phase. However, the $\mathrm{Cu}_{2} \mathrm{~S}$ films prepared by this electrochemical reduction were stable and show unique PL characteristics in spite of the uncertain origin of the light emission. Furthermore, the copper vacancy in roxbyite $\mathrm{Cu}_{1.8} \mathrm{~S}$ dramatically declines the PL intensity. Although 1-DDT molecules could partially reduce the number of copper vacancy in roxbyite $\mathrm{Cu}_{1.8} \mathrm{~S}$ triangular nanoplates, the residual ones result in complete quenching of the PL intensity. ${ }^{86} \mathrm{As}$ a consequence, the presence or absence of LSPR absorption in $\mathrm{Cu}_{2-x} \mathrm{~S}$ NPs should be carefully considered for particular applications.

\section{Plasmonic applications}

In this section, we will focus on the applications of $\mathrm{Cu}_{2-x} \mathrm{~S}$ NPs resulting from their LSPR responses in NIR and MIR regions. In order to comprehend the origin of plasmonic applications, it is worth recalling the sequence of events following absorption/ scattering of photons by a well-known plasmonic Au NP, ${ }^{87}$ which can be somewhat closely correlated with $\mathrm{Cu}_{2-x} \mathrm{~S}$.
In particular, the potential of highly resonant absorption/scattering of NIR and MIR photons and subsequent hole-hole/hole-phonon scattering, vibrational resonance of crystal lattice and coupling to the environment as well as the near electric field enhancement characteristics of $\mathrm{Cu}_{2-x} \mathrm{~S}$ NPs have been well explored for a diversity of applications. (i) The absorbed NIR and MIR light is dissipated to the surrounding medium in the form of heat, making the $\mathrm{Cu}_{2-x} \mathrm{~S}$ NPs as local heat sources and promising candidates for biological applications such as photoacoustic imaging, photothermal therapy as well as other perfect IR absorbers. (ii) The LSPR-induced hot carriers generated via inelastic scattering in $\mathrm{Cu}_{2-x} \mathrm{~S}$ transfer to metal and semiconductor counterparts through heterostructured interface, endowing them suitable for organic synthesis, photo(electro)catalytic water splitting and many others. (iii) The amplification of local electric field intensity by LSPR enables $\mathrm{Cu}_{2-x} \mathrm{~S}$ NPs to enhance two-photon upconversion of luminescent materials and SERS sensitivity.

\subsection{Photoacoustic imaging and photothermal therapy}

After illumination, $\mathrm{Cu}_{2-x} \mathrm{~S}$ NPs can rapidly convert NIR/MIR light energy into heat for photoacoustic imaging (PAI) and photothermal therapy (PTT). Recently, PAI has developed rapidly as a noninvasive biomedical imaging technique that detects the thermoelastic expansion and ultrasonic signals resulted from photothermal expansion of biological tissues after light illumination. This technique is a combination of molecular specificity of optical imaging depth and spatiotemporal resolution of sonography. ${ }^{88,89}$ In the NIR-II region (1000-1700 nm), there is low photon absorption and scattering by biological tissues. As a result, selection of $\mathrm{Cu}_{2-x} \mathrm{~S}$ NPs with intense NIR-II absorption 
as a contrast agent, can effectively improve the quality (signal-tonoise ratio) of PAI. Ku et al. synthesized $11 \mathrm{~nm}$ CuS NPs and used for PAI with a $1064 \mathrm{~nm}$ laser, well within the NIR-II region. The CuS NPs allowed clear imaging of lymph nodes located $12 \mathrm{~mm}$ below the skin surface. Additionally, CuS NPs within agarose gel embedded in chicken breast muscle were imaged at a depth of $\sim 5$ $\mathrm{cm}$ with a high in-plane resolution of $\sim 800 \mu \mathrm{m}$ as well as an imaging sensitivity of $\sim 0.7 \mathrm{nmol}$ per image voxel. ${ }^{90}$ In order to relieve the in vivo toxicity to the blood and normal tissues, Mou et al. prepared ultrasmall $\mathrm{Cu}_{2-x} \mathrm{~S}$ NPs $(<5 \mathrm{~nm})$ with intense LSPR absorption in NIR-II region and employed them as an excellent PAI nanoplatform, to identify the site, size and morphology of the mouse tumor. Moreover, the $\mathrm{Cu}_{2-x} \mathrm{~S}$ NPs can be completely cleaned through feces and urine, implying their high biosafety. ${ }^{91}$ In addition to PAI, PTT also is a noninvasive treatment using NIR light absorbers to generate thermal energy under laser irradiation, leading to elevated local temperatures and irreversible damage to adjacent tumor cells. Compared to traditional cancer therapies such as surgery, chemotherapy as well as radiation therapy, PTT has the merits of low cost and minimal side effects. ${ }^{92,93}$ Therefore, the $\mathrm{Cu}_{2-x} \mathrm{~S}$ NPs composed of earth abundant and nontoxic elements show strong LSPR absorption in NIR-II region, holding great promise in the area of PTT. Ding et al. constructed a dual plasmonic hybrid $\mathrm{Au}-\mathrm{Cu}_{9} \mathrm{~S}_{5}$ core/shell NPs that have high LSPR absorption in NIR-II window and exhibit $50 \%$ higher absorption at $1064 \mathrm{~nm}$ compared to the individual $\mathrm{Cu}_{9} \mathrm{~S}_{5}$ NPs. The core/shell NPs showed large optical absorption cross section, high photothermal transduction efficiency at $37 \%$, large tissue penetration depth, excellent X-ray attenuation ability as well as low cytotoxicity, which enable them for robust photothermal therapy in the NIR-II window with low NP dose as well as laser flux, making them as potential theranostic materials for X-ray CT imaging. ${ }^{94}$ More recently, Zhu et al. used biocompatible $\mathrm{Au} @ \mathrm{Cu}_{2-x} \mathrm{~S}$ NPs for PTT and demonstrated that, under NIR laser irradiation $(808 \mathrm{~nm}$, $1.5 \mathrm{~W} \mathrm{~cm}^{-2}$ ), tumor volume decreased about $50 \%$ in 22 days treatment in the presence of $\mathrm{Au} @ \mathrm{Cu}_{2-x} \mathrm{~S}$ NPs. For control, the same tumor increased by 2-3 times without the NPs. ${ }^{95}$ Chang et al. prepared Au-@void CuS yolk-shell NPs (YSNPs) for "chemophototherapy”. A series of Au NPs with LSPR absorption peaks at 520, 700, 808, 860, and $980 \mathrm{~nm}$ were embedded in CuS hollow NPs to find the most efficient Au-CuS YSNPs according to the resonance energy transfer process. The $\mathrm{Au}_{808 \mathrm{~nm}}-\mathrm{CuS}$ and $\mathrm{Au}_{980 \mathrm{~nm}}-\mathrm{CuS}$ YSNPs were found able of inducing the largest temperature elevation and generating the most significant hydroxyl radicals under the irradiation of 808 and $980 \mathrm{~nm}$ laser, accordingly damaging the most severe $4 \mathrm{~T} 1$ cell through oxidative stress mechanism. ${ }^{96}$ In addition to the tunable Au core@fixed CuS shell dual plasmonic nanocomposites, another strategy is the fabrication of Au core@ variable $\mathrm{Cu}_{2-x} \mathrm{~S}$ shell NPs. Sun et al. selectively grown copper sulfide shells such as covellite ( $\mathrm{CuS})$, digenite $\left(\mathrm{Cu}_{1.8} \mathrm{~S}\right)$, and nonstoichiometric $\mathrm{Cu}_{1.5} \mathrm{~S}$ on the surfaces of $\mathrm{Au} \mathrm{NP}$ cores. This synthetic method provides not only fine control of the core and shell sizes but also adjustment of the hole density in the $\mathrm{Cu}_{2-x} \mathrm{~S}$ shell. The unique multimodal photothermal behaviors of these core@ shell NPs upon selective photoexcitations at their distinct LSPR frequencies, enable the authors to quantitatively evaluate and compare the intrinsic photothermal efficiency of multiple types of hot charge carriers, excited-state lifetimes, energy distributions as well as energy transfer pathways. ${ }^{97}$ Nonetheless, the utilization of high power intensity above therapeutically permissible values, limits their practical applications. Additionally, the size of the core/ shell NPs exceeded $20 \mathrm{~nm}$ in all these studies. To circumvent the above limits to a certain extent, Wang et al. reported the preparation of physiologically stable $6.5 \mathrm{~nm}$ chalcocite/djurleite $\mathrm{Cu}_{2-x} \mathrm{~S}$ NPs with LSPR centered at $1300 \mathrm{~nm}$ and analyzed their PTT efficacy (Fig. 9a and b). ${ }^{98}$ The $\mathrm{Cu}_{2-x} \mathrm{~S}$ NPs demonstrated high photothermal heating and therapy efficiency under an $808 \mathrm{~nm}$ laser with of $0.6 \mathrm{~W} \mathrm{~cm}^{-2}$ power intensity. Interestingly, the $\mathrm{Cu}_{2-x} \mathrm{~S}$ NPs not only worked as photothermal therapy agent, but also as photodynamic therapy (PDT) agent by producing high levels of reactive oxygen species, which are linked to local $\mathrm{Cu}(\mathrm{I})$ release triggered deacetylation reaction of non-fluorescent dye. The combination of PTT and PDT will evoke further investigations on the different therapeutic mechanisms of plasmonic copper chalcogenide NPs.

\subsection{Photocatalytic organic synthesis}

In general, there are two proposed mechanisms for plasmonic $\mathrm{Cu}_{2-x} \mathrm{~S}$ NPs to enhance the photocatalytic performances of organic synthesis, including local heating effect and charge transfer resulting from the hot carrier (hole) generation. In most studies, metal-semiconductor heterostructures were selected for photocatalytic tests, where noble metals such as Pt and Pd work as the catalytic center and $\mathrm{Cu}_{2-x} \mathrm{~S}$ serve as the LSPR component. Cui et al. prepared $\mathrm{Pd} / \mathrm{Cu}_{7} \mathrm{~S}_{4}$ heterostructured NPs and promoted the conversion efficiency of Suzuki coupling reaction, oxidation of benzyl alcohol as well as hydrogenation of nitrobenzene. ${ }^{99}$ The LSPR peak of $\mathrm{Pd} / \mathrm{Cu}_{7} \mathrm{~S}_{4}$ was mainly located in the region of 1500-2000 $\mathrm{nm}$ (Fig. 10a). The authors showed that for all three catalytic reactions, the maximum conversion efficiency was obtained under $1500 \mathrm{~nm}$ laser irradiation (Fig. 10b). The intense LSPR absorption excited by $1500 \mathrm{~nm}$ laser leads to the formation of hot holes in the valence band of $\mathrm{Cu}_{7} \mathrm{~S}_{4}$, some of which possess sufficient energy to overcome the Schottky barrier at the $\mathrm{Cu}_{7} \mathrm{~S}_{4}-\mathrm{Pd}$ interface, and inject into the $\mathrm{Pd}$ domain. The accumulation of hot holes in Pd make it positively charged, serving as a key contribution to the enhancement of photocatalytic activity of $\mathrm{Pd} / \mathrm{Cu}_{7} \mathrm{~S}_{4}$, while the local heating effect only contributes a portion of catalytic activity. Furthermore, in recycling experiments, the $\mathrm{Pd} / \mathrm{Cu}_{7} \mathrm{~S}_{4}$ NPs were stable and could maintain their structures and photocatalytic activity after five cycles. This synthetic strategy can be easily applied to other $\mathrm{Cu}_{7} \mathrm{~S}_{4} @ \mathrm{M}(\mathrm{M}=\mathrm{Pt}, \mathrm{Ag}, \mathrm{Au}) \mathrm{NPs}$, bringing new insights for design and fabrication of highly effective photocatalysts for efficient conversion of solar energy to chemical energy. ${ }^{99}$ In addition, Wang et al. exploited a new and distinctive combination method to prepare a number of Janus-like Pd-dispersed CuS (amorphous PdCuS/partially crystalline CuS) NPs with tailored compositions and proportions via cation exchange, and used for selective semihydrogenation of phenylacetylene. ${ }^{100}$ This synthetic approach promoted not only the utilization efficiency of Pd metal atoms, but also the stability of anchored active sites. By optimizing the amount of 
a

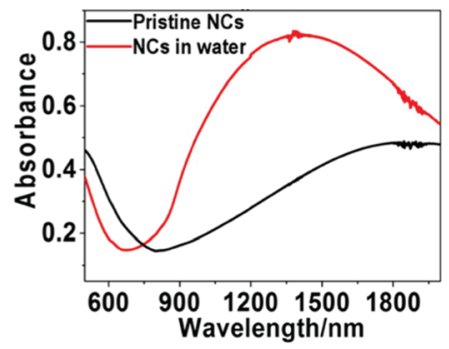

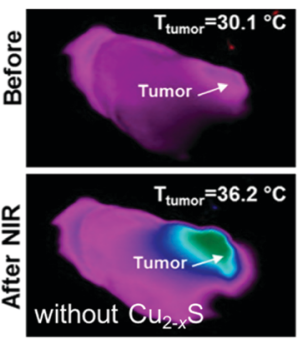

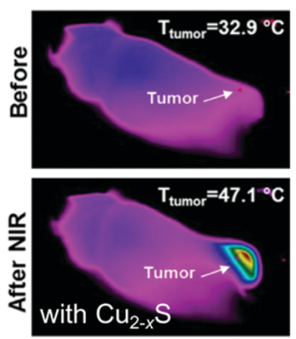

b
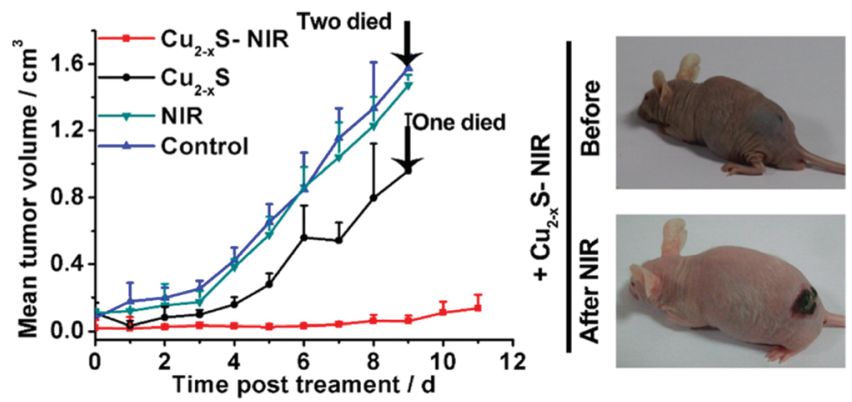

Fig. 9 (a) LSPR absorptions of the $\mathrm{Cu}_{2-x} \mathrm{~S}$ NPs before (black curve) and after (red curve) ligand exchange as well as thermal images of the tumor sites with and without injection of the $\mathrm{Cu}_{2-x} \mathrm{~S} \mathrm{NPs}$. After NIR laser light irradiation, the local temperature of tumor sites with $\mathrm{Cu}_{2-x} \mathrm{~S} \mathrm{NPs} \mathrm{increased} \mathrm{more} \mathrm{rapidly}$ than that of tumor sites without $\mathrm{Cu}_{2-x} \mathrm{~S} N P s$. (b) Variation of mean tumor volume in the control group/NIR group/ $\mathrm{Cu}_{2-x} \mathrm{~S} g r o u p / \mathrm{Cu}_{2-x} \mathrm{~S}-\mathrm{NIR}$ group and images of nude mice taken before and at second day with $\mathrm{Cu}_{2-x} \mathrm{~S}-\mathrm{NIR}$ treatment. (Reproduced with permission from ref. 98 , copyright 2015 American Chemical Society.)

a
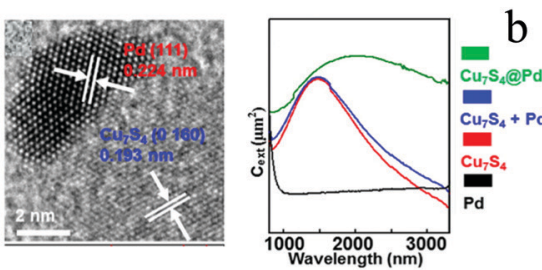

b (i)

(ii)
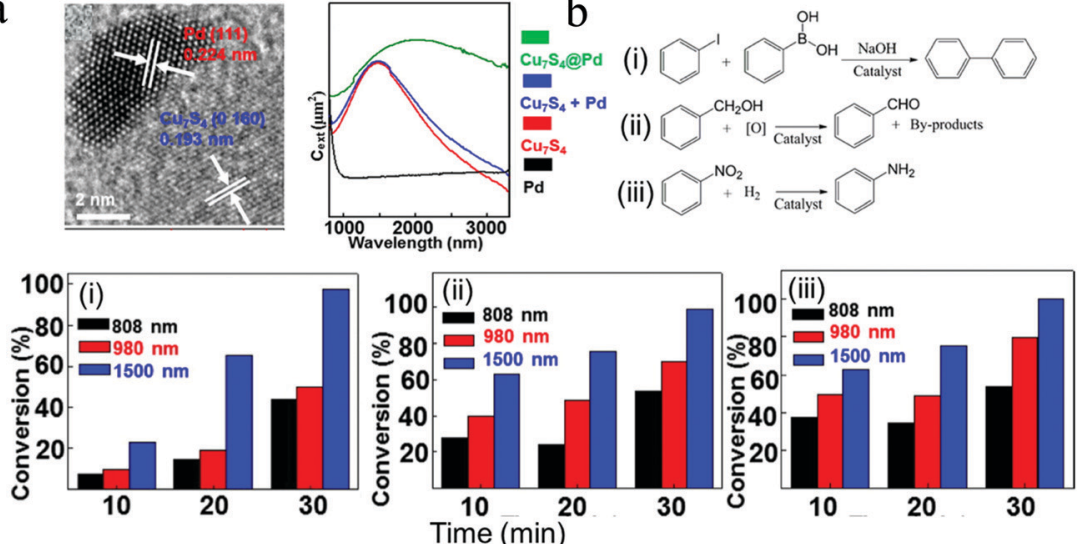

Fig. 10 Photocatalytic organic synthesis by (a) $\mathrm{Pd} / \mathrm{Cu}_{7} \mathrm{~S}_{4}$ heterostructures. (b) Conversion efficiency of (i) Suzuki coupling reaction of iodobenzene with phenylboronic acid, (ii) oxidation of benzyl alcohol, (iii) hydrogenation of nitrobenzene under $808 \mathrm{~nm}, 980 \mathrm{~nm}$ and $1500 \mathrm{~nm}$ laser irradiation $\left(0.45 \mathrm{~W} \mathrm{~cm}^{-2}\right)$ for $30 \mathrm{~min}$. (Reproduced with permission from ref. 99, copyright 2015 American Chemical Society.)

dispersed Pd and deactivation effects from copper and sulfur, the PdCuS/CuS NPs exhibited high catalytic activity with a conversion of $90.3 \%$ and selectivity (towards styrene) of $91.1 \%$. The authors believed that this dispersing a noble metal in a sulfide substrate is a feasible way to achieve effective photocatalysts for organic reactions with superior selectivity, activity and stability.

\subsection{Photo(electro)catalytic water splitting}

Hydrogen production through photocatalytic water splitting using solar energy is an attractive solution to the global energy and environmental issues. ${ }^{101}$ Initialized by Honda-fujishima effect, numerous endeavors have been made to develop efficient photocatalysts for water splitting. ${ }^{102-104}$ However, the solar spectrum used by most photocatalysts is limited to the UV and visible regions. NIR light, which accounts for around $50 \%$ of the solar energy, cannot be efficiently utilized. Thanks to the intense LSPR absorption, $\mathrm{Cu}_{2-x} \mathrm{~S}$ NPs can efficiently use the NIR light. Nevertheless, it is suggested that the ultrafast hot carrier relaxation and annihilative exciton recombination in single $\mathrm{Cu}_{2-x} \mathrm{~S}$ may give rise to low energy conversion efficiency. ${ }^{11,105}$ In order to increase the photocatalytic activity, Lian et al. prepared $\mathrm{Cu}_{7} \mathrm{~S}_{4} / \mathrm{CdS}$ heterostructured NPs and investigated their photocatalytic water splitting performance under NIR light (Fig. 11a and b). ${ }^{106}$ Although the single $\mathrm{Cu}_{2-x} \mathrm{~S}$ NPs exhibit intense LSPR absorption in NIR region, they could not catalyze water splitting under NIR illumination $(\lambda>800 \mathrm{~nm})$. 

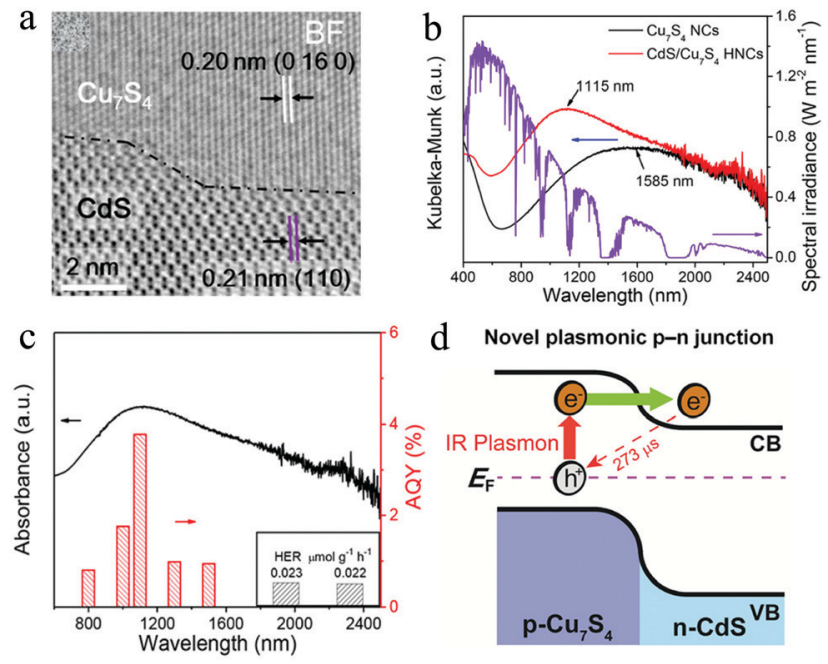

d Novel plasmonic $p-n$ junction

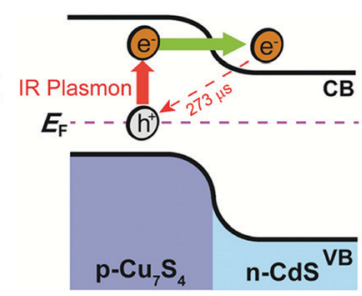

Fig. 11 (a) Photocatalytic $\mathrm{H}_{2}$ evolution over $\mathrm{Cu}_{7} \mathrm{~S}_{4} / \mathrm{CdS}$ NPs under NIR illumination $(\lambda>800 \mathrm{~nm})$ in a $\mathrm{Na}_{2} \mathrm{~S}-\mathrm{Na}_{2} \mathrm{SO}_{3}$ aqueous buffer solution $(\mathrm{pH}=12)$. ( $b$ and $\mathrm{c})$ Absorption spectrum and apparent quantum yield for $\mathrm{H}_{2}$ evolution of the $\mathrm{Cu}_{7} \mathrm{~S}_{4} / \mathrm{CdS} \mathrm{NPs}$ under the monochromic light illumination $\left(6 \mathrm{~mW} \mathrm{~cm}^{-2}\right)$ demonstrating the efficient NIR light to hydrogen conversion. (d) NIR plasmon induced hot electron generation and interfacial migration. (Reproduced with permission from ref. 106, copyright 2019 American Chemical Society.)

Furthermore, a mixture of the $\mathrm{Cu}_{7} \mathrm{~S}_{4}$ and CdS NPs did not promote the $\mathrm{H}_{2}$ evolution, demonstrating the great importance of intimate heterostructure interface between these two components. The apparent quantum yield (AQY) of $\mathrm{Cu}_{7} \mathrm{~S}_{4} / \mathrm{CdS}$ NPs reached $3.8 \%$ at $1100 \mathrm{~nm}$, which is much higher than other NIR active composites such as $\mathrm{Pt}-\mathrm{W}_{18} \mathrm{O}_{49} / \mathrm{g}-\mathrm{C}_{3} \mathrm{~N}_{4}$ heterostructure, Pt-modified $\mathrm{Au}$ NRs and $\mathrm{Au} \mathrm{NRs} / \mathrm{La}_{2} \mathrm{Ti}_{2} \mathrm{O}_{7}$ (Fig. 11c). ${ }^{107-109}$ The transient absorption results revealed that LSPR-induced hot electron transfer from $\mathrm{Cu}_{7} \mathrm{~S}_{4}$ to $\mathrm{CdS}$ realizes long-lived charge separation $(>273 \mu \mathrm{s})$, leading to high NIR light to hydrogen conversion efficiency (Fig. 11d). Furthermore, Bhavani et al. prepared hollow skeletal-type $\mathrm{Cu}_{7} \mathrm{~S}_{4}$ superstructures integrated with CdS NRs and investigated their photocatalytic hydrogen generation via water splitting under solar light irradiation using lactic acid as a hole scavenger. ${ }^{110}$ The $\mathrm{Cu}_{7} \mathrm{~S}_{4} / \mathrm{CdS}$ composite exhibited a 3 times higher $\mathrm{H}_{2}$ generation rate than that of single CdS. Moreover, an addition of a small amount of nickel salts to the reaction solution in order to produce a Ni- $\mathrm{Cu}_{7} \mathrm{~S}_{4} / \mathrm{CdS}$ composite, dramatically improved the photocatalytic $\mathrm{H}_{2}$ generation, with an activity 20 times higher than the single CdS and 7 times higher than the $\mathrm{Cu}_{7} \mathrm{~S}_{4} / \mathrm{CdS}$. The authors suggested that the enhancement of photocatalytic activity in $\mathrm{Ni}-\mathrm{Cu}_{7} \mathrm{~S}_{4} / \mathrm{CdS}$ composite could be attributed to effective charge carrier separation by the unique properties of the skeletal-type $\mathrm{Cu}_{7} \mathrm{~S}_{4}$ cages as well as superior charge transportation by the $\mathrm{Ni}$ salts in the reaction solution. ${ }^{110}$ Along similar lines, Zhang et al. decorated the hierarchical $\mathrm{Cu}_{7} \mathrm{~S}_{4} /$ $\mathrm{ZnIn}_{2} \mathrm{~S}_{4}$ with black phosphorus quantum dots (BPQDs) and investigated the photocatalytic hydrogen production under the irradiation of wavelength $\lambda>420 \mathrm{~nm}$. ${ }^{111}$ The intimate hierarchical structure of $\mathrm{Cu}_{7} \mathrm{~S}_{4}$ with $\mathrm{ZnIn}_{2} \mathrm{~S}_{4}$ and carrier separation ability by BPQDs were synergistically beneficial for boosting the photocatalytic activity of $\mathrm{H}_{2}$ generation with a rate about 6.8 times higher than that of the pristine $\mathrm{ZnIn}_{2} \mathrm{~S}_{4}{ }^{111}$ More recently, complex structure such as n-p-n type CdS@ $\mathrm{Cu}_{2-x} \mathrm{~S}-\mathrm{MoS}_{2}$ and p-n-p type $\mathrm{Cu}_{2-x} \mathrm{~S} @ \mathrm{CdS}-\mathrm{Bi}_{2} \mathrm{~S}_{3}$ nanocomposites have been fabricated for efficient photocatalytic $\mathrm{H}_{2}$ generation. ${ }^{112,113}$ Liu et al. successfully prepared a specific stratified $\mathrm{CdS} @ \mathrm{Cu}_{2-x} \mathrm{~S}-\mathrm{MoS}_{2}$ NPs with the $\mathrm{MoS}_{2}$ nanosheets epitaxially and vertical to the surface of $\mathrm{CdS} @ \mathrm{Cu}_{2-x} \mathrm{~S}$ NRs by applying cation exchange and subsequent seeding growth. This stratified heterostructures exhibited high photocatalytic activity $(\lambda>400 \mathrm{~nm})$ for $\mathrm{H}_{2}$ generation via water splitting at a rate of rate of $14184.8 \mu \mathrm{mol} \mathrm{g}^{-1} \mathrm{~h}^{-1}$ in the absence of any noble metal cocatalysts, which is 12.7 and 97.2 times higher than that of $\mathrm{CdS} @ \mathrm{Cu}_{2-x} \mathrm{~S}$ and pure CdS and is comparable to the activity of Pt-decorated $\mathrm{CdS} @ \mathrm{Cu}_{2-x} \mathrm{~S}$. This superior photocatalytic performance was ascribed to fast charge separation and migration within the framework originated from the unique heterostructure and efficient $\mathrm{Cu}^{\mathrm{I}} @ \mathrm{MoS}_{2}\left(\mathrm{Cu}^{\mathrm{I}}\right.$-intercalated within the $\left.\mathrm{MoS}_{2}\right)$ catalytic and protective layers as well as the strong $\mathrm{Cu}_{2-x} \mathrm{~S}$ light exciton resonance absorption. ${ }^{112}$ In addition, Guo et al. reported the design and fabrication of tandem $\mathrm{Cu}_{2-x} \mathrm{~S} @ \mathrm{CdS}-\mathrm{Bi}_{2} \mathrm{~S}_{3}$ sandwich heterojunctions with well-defined structures and interfaces via a continuous growth deposition method on the surface of preformed hollow $\mathrm{Cu}_{2-x} \mathrm{~S}$ octahedron (Fig. 12a and b). ${ }^{113}$ The unique sandwich-layered hollow nanostructure can provide large specific surface areas and sufficient reaction sites and promote the charge separation and migration.

Furthermore, the $\mathrm{p}-\mathrm{n}-\mathrm{p}$ heterojunction coupled with hot electron transfer by the LSPR effect of $\mathrm{Cu}_{2-x} \mathrm{~S}$ increased the photocatalytic $\mathrm{H}_{2}$ generation performance (Fig. 12c). The optimized $\mathrm{Cu}_{2-x} \mathrm{~S} / \mathrm{CdS} / \mathrm{Bi}_{2} \mathrm{~S}_{3}$ photocatalyst exhibited a remarkable $\mathrm{H}_{2}$ generation rate of $8012 \mu \mathrm{mol} \mathrm{h}{ }^{-1}$ much higher than the other 3 test samples and the excellent stability of this ternary hollow nanostructure is beneficial to practical applications (Fig. 12d and e). Another working strategy to increase the water splitting efficiency of $\mathrm{Cu}_{2-x} \mathrm{~S}$ is to control the location and distribution of copper vacancies. Ren et al. reported the synthesis of surficially defective $\mathrm{Cu}_{1.94} \mathrm{~S}$ nanoflake arrays (NFAs) photocathode from $\mathrm{Cu}$ foil, i.e., $\mathrm{Cu}-\left(\mathrm{Cu}_{2} \mathrm{~S} @ \mathrm{Cu}_{1.94} \mathrm{~S}\right) .{ }^{114}$ The surficial copper vacancies can serve as adsorptive and catalytic sites for water splitting, and the defect free internal $\mathrm{Cu}_{2} \mathrm{~S}$ transport holes rapidly to the external circuit. Under full-spectrum (300-2500 nm, $200 \mathrm{~mW} \mathrm{~cm}^{-2}$ ) illumination, the LSPR of $\mathrm{Cu}_{2-x} \mathrm{~S}$ NFAs enhance light harvesting and lead to rapid generation of electron-hole pairs in the near surface layer. The electrons readily separate from the holes and immigrate rapidly to the catalytic sites, where they reduce water molecules into $\mathrm{H}_{2}$. As a result, the presence of copper vacancy and LSPR effect in $\mathrm{Cu}_{2-x} \mathrm{~S}$, improves the photoelectrocatalytic performance to an altitude of 2.67 times than that of defect free NFAs, which cannot take advantages of catalytic activity and LSPR effect. This intentional defect engineering is a promising way to the current challenges in solar energy conversion systems.

\subsection{Two-photon upconversion}

$\mathrm{Cu}_{2-x} \mathrm{~S}$ NPs demonstrate not only tunable LSPR but also a two absorption effect under infrared light excitation, offering a novel "all-in-one" platform for investigating exciton-plasmon 

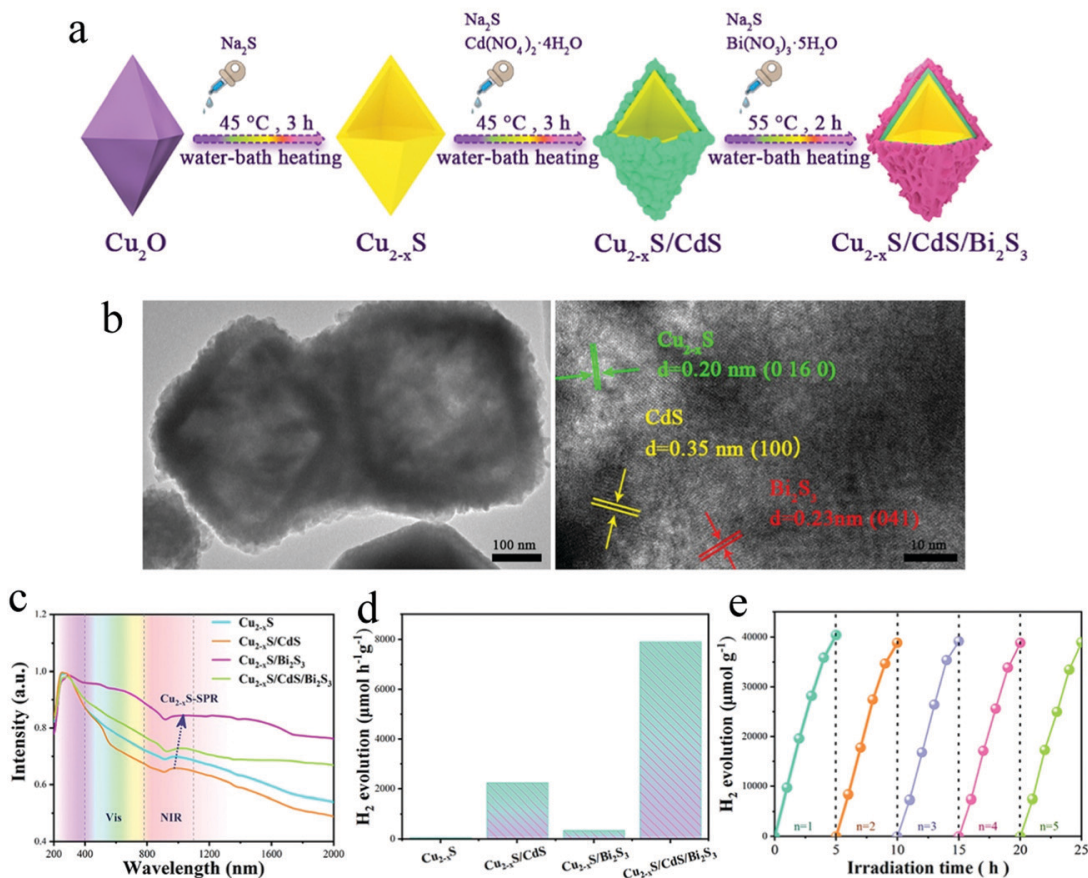

Fig. 12 (a) Fabrication process for the sandwich-layered $\mathrm{Cu}_{2-x} \mathrm{~S}\left(\mathrm{C} d \mathrm{~S}-\mathrm{Bi}_{2} \mathrm{~S}_{3}\right.$ octahedral heterostructure. (b) TEM images of the prepared samples indicate the presence of large surface areas and intimate interfaces. (c) UV-vis-NIR absorption spectra of four test samples: $\mathrm{Cu}_{2-x} \mathrm{~S}, \mathrm{Cu}_{2-x} \mathrm{~S} / \mathrm{CdS}$, $\mathrm{Cu}_{2-x} \mathrm{~S}_{/} \mathrm{Bi}_{2} \mathrm{~S}_{3}$ and $\mathrm{Cu}_{2-x} \mathrm{~S} / \mathrm{CdS} / \mathrm{Bi}_{2} \mathrm{~S}_{3}$. (d) Photocatalytic $\mathrm{H}_{2}$ generation of four test samples and (e) $\mathrm{H}_{2}$ generation stability tests of 100 mg Cu $2-x \mathrm{~S} / \mathrm{CdS} /$ $\mathrm{Bi}_{2} \mathrm{~S}_{3}$ under vis-NIR illumination $(\lambda>420 \mathrm{~nm})$ in a methanol/ $\mathrm{H}_{2} \mathrm{O}$ aqueous solution. (Reproduced with permission from ref. 113 , copyright 2020 American Chemical Society.)

coupling without a physical or chemical interface. Marin et al. reported the synthesis of selenium doped CuS NDs and demonstrated the two-photon upconversion effect and the role of LSPR on fluorescence emission. ${ }^{115}$ Owing to the energy alignment of the CuS bandgap at twice the LSPR, the CuS NDs exhibit self-enhanced emission (Fig. 13a). The authors measured the emission intensity of CuS as a function of the power of the excitation laser. As expected, one-photon absorption gives a linear relationship, while multiphoton absorption gives rise to a nonlinear relationship between emission intensity and excitation power. ${ }^{116}$ For a perfect two-photon process, the emission intensity varies with the square of excitation power. ${ }^{117} \mathrm{~A}$ slope of 1.87 and 2.37 is observed upon increasing and decreasing of the laser power, which is closely correlated with the power-squared dependence (slope $=2$ ) of a two-photon absorption process. Furthermore, the authors studied the effect of LSPR of CuS NDs on the emission intensity using selenium doping. A blue-shift of the LSPR peak toward the two-photon absorption edge of the Se doped CuS samples, a 3-fold enhancement of emission was observed, indicating that these CuS NPs hold great potential for applications such as bioimaging and photodynamic therapy which require multiphoton absorption. In addition to self-enhanced emission of $\mathrm{Cu}_{2-x} \mathrm{~S}$ NPs, Zhou et al. exploited upconversion luminescence enhancement of $\mathrm{NaYF}_{4}: \mathrm{Yb}^{3+}, \mathrm{Er}^{3+} \mathrm{NPs}$ induced by $\mathrm{Cu}_{2-x} \mathrm{~S}$ NPs. ${ }^{118}$ The authors prepared a three-layered $\mathrm{Cu}_{2-x} \mathrm{~S}-$ $\mathrm{MoO}_{3}-\mathrm{NaYF}_{4}$ hybrid film consisting of plasmonic $\mathrm{Cu}_{2-x} \mathrm{~S}$ NPs as the bottom layer, $\mathrm{MoO}_{3}$ with a suitable thickness $(8 \mathrm{~nm})$ as a separator layer, and upconversion NPs as the top layer to investigate the power-dependent red, green, and blue emission from the upconversion NPs. The extraordinary power-dependent behavior of the hybrid film was explained by the interaction mechanism between plasmonic $\mathrm{Cu}_{2-x} \mathrm{~S}$ NPs and $\mathrm{NaYF}_{4}: \mathrm{Yb}^{3+}, \mathrm{Er}^{3+}$ upconversion NPs, i.e., plasmon scattering effect at lower excitation power intensity and electron diffusion by a two-photon interband transition in $\mathrm{Cu}_{2-x} \mathrm{~S} \mathrm{NP}$ at higher power intensity. ${ }^{118}$ Subsequently, they synthesized $\mathrm{Cu}_{2-x} \mathrm{~S} @ \mathrm{SiO}_{2} @ \mathrm{Y}_{2} \mathrm{O}_{3}: \mathrm{Yb}^{3+} / \mathrm{Er}^{3+}$ core-shell nanocomposites and experimentally and theoretically investigated the LSPR induced upconversion enhancement. An enhancement of approximately 30-fold was obtained compared with the sample without $\mathrm{Cu}_{2-x} \mathrm{~S}$, that is $\mathrm{SiO}_{2} @ \mathrm{Y}_{2} \mathrm{O}_{3}: \mathrm{Yb}^{3+} / \mathrm{Er}^{3+}$. This enhancement was induced by a combination effect of the amplification of the excitation field and an increase of resonance energy transfer rate from $\mathrm{Yb}^{3+}$ to $\mathrm{Er}^{3+}{ }^{119}$ Furthermore, the authors introduced photonic crystals (PCs) to manipulate the localized electric fields of $\mathrm{Cu}_{2-x} \mathrm{~S}$ and explored to enhance the upconversion luminescence of $\mathrm{NaYF}_{4}: \mathrm{Yb}^{3+}, \mathrm{Er}^{3+} @ \mathrm{NaYF}_{4}: \mathrm{Yb}^{3+}, \mathrm{Nd}^{3+} \mathrm{NPs}^{120}$ In the PMMA OPC/ $/ \mathrm{Cu}_{2-x} \mathrm{~S} / \mathrm{MoO}_{3} / \mathrm{NaYF}_{4}$ hybrids, due to the extra contribution of the PC effect, upconversion enhancement factor reached to hundreds to thousands of fold, which is strongly dependent on the crystal structure of $\mathrm{Cu}_{2-x} \mathrm{~S}$ and excitation wavelength (Fig. 13b). Obviously, the $\mathrm{Cu}_{1.8} \mathrm{~S}$ hybrid yielded much stronger enhancement factor than that of the CuS hybrid. The optimized enhancement factor under $980 \mathrm{~nm}$ lase excitation for the $\mathrm{OPC} / \mathrm{Cu}_{1.8} \mathrm{~S} / \mathrm{MoO}_{3} / \mathrm{NaYF}_{4}: \mathrm{Yb}^{3+}, \mathrm{Er}^{3+} @ \mathrm{NaYF}_{4}: \mathrm{Yb}^{3+}, \mathrm{Nd}^{3+}$ hybrids was nearly 1500 -fold for whole light emission, 2000-fold for green light emission and 1200-fold for red light emission. It is suggested 

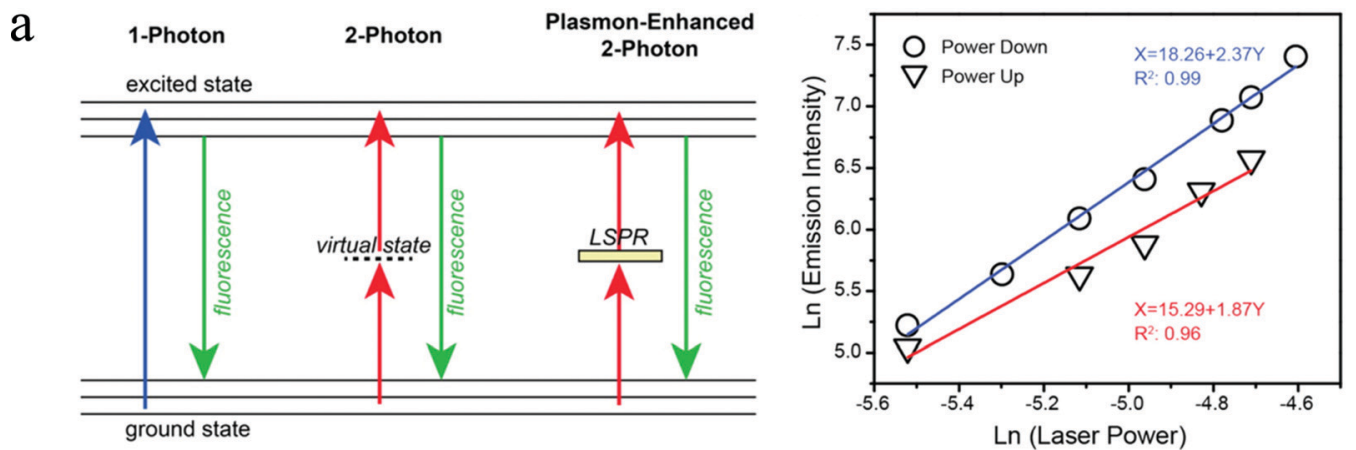

b
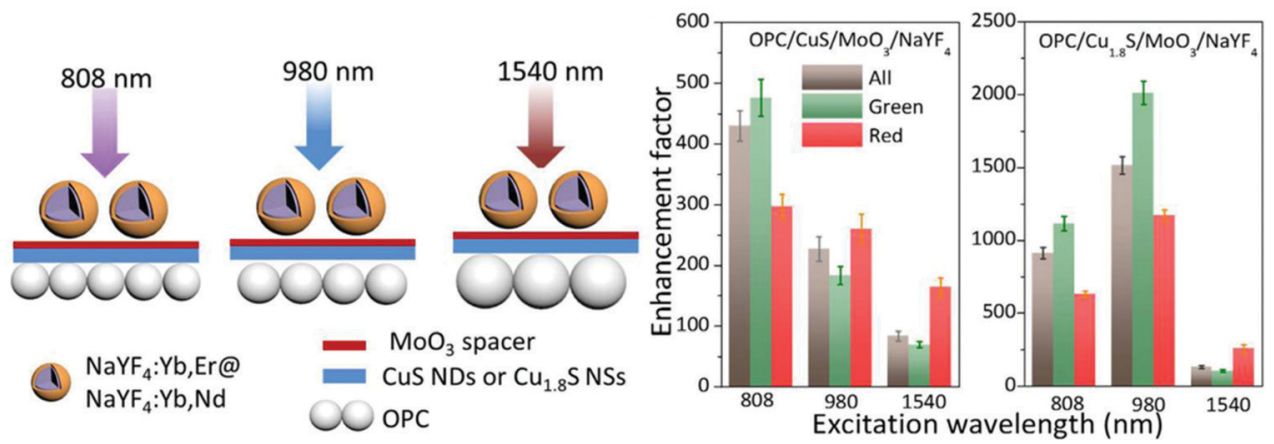

Fig. 13 LSPR coupling with excitonic transitions. (a) Scheme of LSPR enhanced upconversion and log-log plot of the power-square dependence of emission intensity of CUS NDs. Nonlinear relationship between emission and incident laser power as well as slope being close to 2 on a log-log scale indicates the possibility of two photon upconversion process. (Reproduced with permission from ref. 115, copyright 2016 American Chemical Society.) (b) Scheme of $\mathrm{Cu}_{2-x} \mathrm{~S}$ crystal structure dependent excitation and emission of two-photon upconversion OPC/Cu${ }_{2-x} \mathrm{~S} / \mathrm{MoO}_{3} / \mathrm{NaYF}_{4}$ hybrids $(808 \mathrm{~nm}$ light at $1.25 \mathrm{~W} \mathrm{~mm}^{-2}, 980$ and $1540 \mathrm{~nm}$ light at $0.15 \mathrm{~W} \mathrm{~mm}^{-2}$ ). (Reproduced with permission from ref. 120, copyright 2017 American Chemical Society.)

that such a high enhancement for the above hybrid can be ascribed to the amplified local electric field by PC effect and LSPR effect, as well as energy transfer from $\mathrm{Cu}_{2-x} \mathrm{~S}$ to $\mathrm{NaYF}_{4}: \mathrm{Yb}^{3+}, \mathrm{Er}^{3+}$ @ $\mathrm{NaYF}_{4}: \mathrm{Yb}^{3+}, \mathrm{Nd}^{3+}$ resulted from the two-photon absorption of $\mathrm{Cu}_{2-x} \mathrm{~S}$ NPs. ${ }^{120}$

\subsection{SERS probe}

Recently, Raman imaging using surface-enhanced Raman scattering (SERS) probes has attracted numerous attention and a large number of efforts have been made on designing highly sensitive SERS probes, including most common noble metallic gold or silver NPs, and several semiconducting materials. ${ }^{121-124}$ However, most of the reported SERS probes are not degradable and therefore they cannot be completely removed from the imaged tissue. To circumvent the current limitation, Qiu et al. explored a photodegradable SERS probe using hollow CuS NPS with an outer encapsulation of poly (ethylene glycol) (PEG). By incorporation with Raman-active reporters such as 3,3'-diethylthiatricarbocyanine iodide (DTTC), the biocompatible DTTChollow CuS NPs can serve as a novel in vivo SERS probe (Fig. 14a). ${ }^{125}$ Under $785 \mathrm{~nm}$ laser irradiation, a significant Raman signal intensity enhancement was observed for the DTTC-hollow CuS NPs, while it is faint for the DTTC adsorbed CuS single crystal (Fig. 14b). Furthermore, the DTTC-hollow CuS probe is stable during the incubation in the serum, demonstrating their potential applications in oncology surgery. Firstly, the DTTC-hollow CuS NPS were preoperatively injected into tumor tissues and after resection of the visible ones, the authors used $785 \mathrm{~nm}$ laser $(10 \mathrm{~mW})$ to excite the Raman signals of DTTC-hollow CuS NPs for residual tumor visualization. Then, they applied $980 \mathrm{~nm}$ laser $(800 \mathrm{~mW}$, $3 \mathrm{~min}$ ) to start the hyperthermia for residual tumor ablation. Finally, by continuous irradiation for $5 \mathrm{~min}$, the large hollow $\mathrm{CuS}$ NPs were degraded into small individual crystals, accelerating their self-clearance from imaged tissues (Fig. 14c). However, the low enhancement factor of $\mathrm{Cu}_{2-x} \mathrm{~S}$ SERS probe in some cases is a major obstacle limiting their practical applications. Therefore, it is desirable to explore the facile synthetic strategies for $\mathrm{Cu}_{2-x} \mathrm{~S}$ NPs and reveal the SERS enhancement mechanism. Chen et al. developed a facile method to synthesize copper sulfide based nanostructures with different $\mathrm{Cu}_{7.2} \mathrm{~S}_{4}$ contents by the annealing of CuS nanosheets at different temperatures. ${ }^{126}$ Compared with pure $\mathrm{CuS}$ or pure $\mathrm{CuSO}_{4}$ (annealing temperature at $350{ }^{\circ} \mathrm{C}$ ), the sample with a higher $\mathrm{Cu}_{7.2} \mathrm{~S}_{4}$ content exhibited lower detection limit of R6G molecules, indicating the SERS performance enhancement by an introduction of nonstoichiometric $\mathrm{Cu}_{7.2} \mathrm{~S}_{4}$. Furthermore, the DFT theoretical calculations indicate that the excellent SERS behavior by $\mathrm{Cu}_{7.2} \mathrm{~S}_{4}$ is dependent on the charge transfer resonance. ${ }^{126}$ In addition to the CuS SERS biological probe, Bao et al. presented an isotropic shell growth of homogeneous CuS on plasmonic Au NPs, exhibiting an efficient SERSbased probe for detection of trace heavy-metal ions. For example,

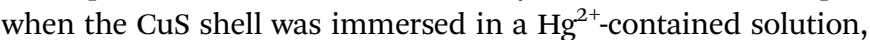
the $\mathrm{Cu}^{+}$in the shell can capture and react with $\mathrm{Hg}^{2+}$ through cation exchange, in situ forming a new HgS shell on the $\mathrm{Au}$ surface (Fig. 14d). ${ }^{127}$ Because of the distinctive vibration energy between $\mathrm{CuS}$ and $\mathrm{HgS}$, the authors can thus realize the $\mathrm{Hg}^{2+}$ 
a

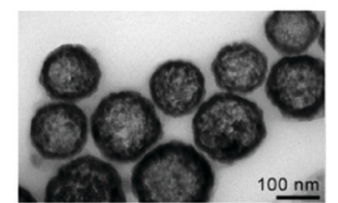

$\mathrm{b}$

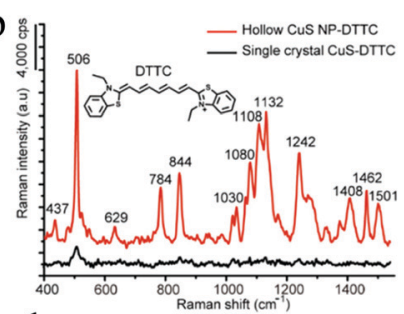

d

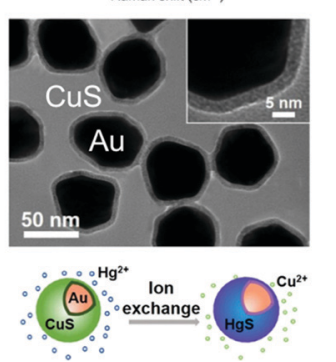

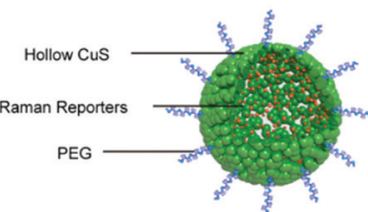

C ${ }_{100} \square$ CuSSERS

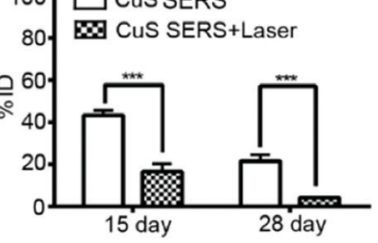

e

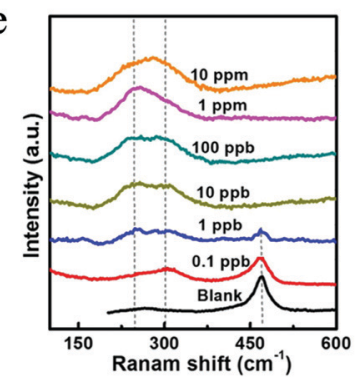

Fig. 14 (a) SERS probe of DTTC \& PEG-hollow CuS NPs and (b) SERS signal enhancement of DTTC molecules by hollow CuS NPs. (c) In vivo photodegradation of above hollow CuS NPs under laser irradiation. The laser-induced photothermal effect accelerated the clearance of hollow CuS probes from tumors over 15 day and 28 day. (Reproduced with permission from ref. 125, copyright 2019 American Chemical Society.) (d) Au@CuS SERS probe for trace heavy-metal ions detection by cation exchange. (e) Evolution of SERS signals of the Au@CuS NPs to the $\mathrm{Hg}^{2+}$ contained solutions with different concentrations. (Reproduced with permission from ref. 127, copyright 2019 American Chemical Society.)

detection by subsequent SERS measurement. The CuS shell shows a peak at $470 \mathrm{~cm}^{-1}$, which originates from the disulfide bond vibration. ${ }^{128,129}$ After immersion in $\mathrm{Hg}^{2+}$ solution, the initial $470 \mathrm{~cm}^{-1}$ peak vanished and two new peaks at 250 and $305 \mathrm{~cm}^{-1}$ evolved, which matches well with the first-order $\mathrm{A}_{1}$ and E vibration in $\mathrm{HgS}$, respectively. ${ }^{130}$ With the SERS signal enhancement by Au and CuS NPs, the limit of $\mathrm{Hg}^{2+}$ detection of $\mathrm{Au} @ \mathrm{CuS}$ reaches to $<0.1 \mathrm{ppb}$, which is better compared with the reported values (Fig. 14e). More important, this detection technique has strong anti-interference to the environments, even with a concentrated common metal ions or high acidity, demonstrating good practical applications.

\section{Conclusion and outlook}

In this review, we have briefly summarized the LSPR of $\mathrm{Cu}_{2-x} \mathrm{~S}$ NPs and their plasmonic applications. In particular, the tunable hole density, various crystal structures and stoichiometries, controllable morphology, hot carrier generation, elevated local temperature as well as locally enhanced electric field make the $\mathrm{Cu}_{2-x} \mathrm{~S}$ NPs suitable for a wide range of applications, ranging from plasmonic heating, photocatalysis, two-photon upconversion, SERS probe and many others. In spite of substantial

progress made in understanding the LSPR of $\mathrm{Cu}_{2-x} \mathrm{~S}$ NPs and their applications, there still remain numbers of open concerns relating to the NP synthesis, chemistries, physics, optical modulation and industrial applications. We list some of representative questions as follows:

(i) In $\mathrm{Cu}_{2-x} \mathrm{~S}$ with a special crystal structure, it is of great importance to investigate the structural variations upon chemical(electro) redox post-treatment, which may largely affect the parameters of its dielectric function. That is vitally important for a more reasonable estimation of the hole density of $\mathrm{Cu}_{2-x} \mathrm{~S}$ NPS from their optical spectra.

(ii) Direct in situ mapping the number of copper vacancy and its distribution in $\mathrm{Cu}_{2-x} \mathrm{~S}$ NP is also important to accurately determine its plasmon oscillation mode. In general, the oscillation mode is determined by the simulation methods such as discrete dipole approximation (DDA) and finite different time domain (FDTD), which may lead to disagreement with the experimental optical spectra of $\mathrm{Cu}_{2-x} \mathrm{~S}$ NPs with different crystal structures and morphologies. The direct copper vacancy mapping is challenging because of the limited spatial resolution of TEM and the low hole density. Further difficulty is the high mobility of $\mathrm{Cu}^{+}$in the NP, which is prone to be damaged by the electron beam during analysis.

(iii) The local electric field enhancement in the near surface region of $\mathrm{Cu}_{2-x} \mathrm{~S} \mathrm{NP}$ is still low. Optimizing the size, morphology, hole density and its spatial distribution of the NP may increase its enhancement factor. Another feasible approach is to employ the plasmon coupling effect to generate hot-spots, where the ultrahigh electric field intensity can greatly improve excitation efficiency of the LSPR related applications.

(iv) The surface chemistry of interaction between surface ligands and surface free holes of $\mathrm{Cu}_{2-x} \mathrm{~S}$ is not well investigated. For photocatalysis, ionic ligands with positive/negative charges are usually needed to ascertain the $\mathrm{Cu}_{2-x} \mathrm{~S}$ NPs high dispersity in aqueous solutions. How do interfacial electrostatic attraction/ repulsion affect the LSPR behavior of $\mathrm{Cu}_{2-x} \mathrm{~S}$ NPs and thus their photocatalytic performances?

(v) $\mathrm{Cu}_{2-x} \mathrm{~S}$ NP used as plasmonic heater: practical considerations such as cost, heating efficiency, NP stability, biosafety and NP clearance should be carefully investigated for any possible practical biological applications. Moreover, a comprehensive study considering both performance and practicality metrics should be conducted over a wide selection of plasmonic materials including not only the $\mathrm{Cu}_{2-x} \mathrm{~S}$, but also metal oxides, metal nitrides, doped silicon and many others, making optical matches for specialized applications.

(vi) The heterostructure interface between $\mathrm{Cu}_{2-x} \mathrm{~S}$ domain and metal domain or semiconductor domain, which plays an important role in determining the hole transfer efficiency for photocatalysis, is not well studied. Which is the crystal planes of $\mathrm{Cu}_{2-x} \mathrm{~S}$ favoring the hole accumulation? How can selectively load the metal or semiconductor domain on these hole-preferred planes to build intimate interfaces? Furthermore, construction of two-dimensional interface between $\mathrm{Cu}_{2-x} \mathrm{~S}$ and other semiconductor for efficient hole transfer may be another promising strategy. In addition to the interface, the directional dependence 
of plasmon oscillation mode in $\mathrm{Cu}_{2-x} \mathrm{~S}$ component also plays a major role.

(vii) Large scale synthesis of $\mathrm{Cu}_{2-x} \mathrm{~S}$ NPs with desired LSPR to meet application demands in future may need development in manufacturing techniques with quality control. How can industrial scale (post)synthetic strategies be innovated while without losing the rigid control over particle size, morphology, doping level as well as crystal structure for a manifold of industrial applications?

\section{Conflicts of interest}

There are no conflicts of interest to declare.

\section{Acknowledgements}

This work was financially supported by the Natural Science Foundation (no. LQ19B010002) and Postdoctoral Foundation of Zhejiang Province.

\section{Notes and references}

1 S. Linic, P. Christopher and D. B. Ingram, Plasmonic-metal nanostructures for efficient conversion of solar to chemical energy, Nat. Mater., 2011, 10, 911-921.

2 C. Clavero, Plasmon-induced hot-electron generation at nanoparticle/metal-oxide interfaces for photovoltaic and photocatalytic devices, Nat. Photonics, 2014, 8, 95-103.

3 A. Agrawal, S. H. Cho, O. Zandi, S. Ghosh, R. W. Johns and D. J. Milliron, Localized surface plasmon resonance in semiconductor nanocrystals, Chem. Rev., 2018, 118, 3121-3207.

4 M. Kanehara, H. Koike, T. Yoshinaga and T. Teranishi, Indium tin oxide nanoparticles with compositionally tunable surface plasmon resonance frequencies in the near-IR region, J. Am. Chem. Soc., 2009, 131, 17736-17737.

5 R. Buonsanti, A. Llordes, S. Aloni, B. A. Helms and D. J. Milliron, Tunable infrared absorption and visible transparency of colloidal aluminum-doped zinc oxide nanocrystals, Nano Lett., 2011, 11, 4706-4710.

6 L. D. Trizio, R. Buonsanti, A. M. Schimpf, A. Llordes, D. R. Gamelin, R. Simonutti and D. J. Milliron, Nb-doped colloidal $\mathrm{TiO}_{2}$ nanocrystals with tunable infrared absorption, Chem. Mater., 2013, 25, 3383-3390.

7 H. F. Cheng, T. Kamegawa, K. Mori and H. Yamashita, Surfactant-free nonaqueous synthesis of plasmonic molybdenum oxide nanosheets with enhanced catalytic activity for hydrogen generation from ammonia borane under visible light, Angew. Chem., Int. Ed., 2014, 53, 2910-2914.

8 Q. Q. Huang, S. Hu, J. Zhuang and X. Wang, $\mathrm{MoO}_{3-\mathrm{x}}$-based hybrids with tunable localized surface plasmon resonances: chemical oxidation driving transformation from ultrathin nanosheets to nanotubes, Chem. - Eur. J., 2012, 18, 15283-15287.

9 K. Manthiram and A. P. Alivisatos, Tunable localized surface plasmon resonances in tungsten oxide nanocrystals, J. Am. Chem. Soc., 2012, 134, 3995-3998.
10 K. S. Schramke, Y. X. Qin, J. T. Held, K. A. Mkhoyan and U. R. Kortshagen, Nonthermal plasma synthesis of titanium nitride nanocrystals with plasmon resonances at nearinfrared wavelengths relevant to photothermal therapy, ACS Appl. Nano Mater., 2018, 1, 2869-2876.

11 I. Kriegel, C. Y. Jiang, J. R. Fernández, R. D. Schaller, D. V. Talapin, E. da Como and J. Feldmann, Tuning the excitonic and plasmonic properties of copper chalcogenide nanocrystals, J. Am. Chem. Soc., 2012, 134, 1583-1590.

12 X. J. Wu, X. Huang, X. Y. Qi, H. Li, B. Li and H. Zhang, Copper-based ternary and quaternary semiconductor nanoplates: templated synthesis, characterization, and photoelectrochemical properties, Angew. Chem., Int. Ed., 2014, 53, 8929-8933.

13 O. Elimelech, J. Liu, A. M. Plonka, A. I. Frenkel and U. Banin, Size dependence of doping by a vacancy formation reaction in copper sulfide nanocrystals, Angew. Chem., Int. Ed., 2017, 56, 10335-10340.

14 H.-L. Wu, R. Sato, A. Yamaguchi, M. Kimura, M. Haruta, H. Kurata and T. Teranishi, Formation of pseudomorphic nanocages from $\mathrm{Cu}_{2} \mathrm{O}$ nanocrystals through anion exchange reactions, Science, 2016, 351, 1306-1310.

15 R. M. C. Castro, M. Casavola, M. van Schilfgaarde, A. V. Krasavin, M. A. Green, D. Richards and A. V. Zayats, Anisotropic plasmonic CuS nanocrystals as a natural electronic material with hyperbolic optical dispersion, ACS Nano, 2019, 13, 6550-6560.

16 H. K. D. Le, H. Y. Xiong, B. A. Page, L. F. G. Herrera, H. P. McAllister, B. C. Li, H. Y. Wang and K. E. Plass, Effects of $\mathrm{I}_{2}$ on $\mathrm{Cu}_{2-x} \mathrm{~S}$ nanoparticles: enabling cation exchange but complicating plasmonics, ACS Mater. Lett., 2020, 2, 140-146.

17 N. Li, D. D. Yin, L. L. Xu, H. Y. Zhao, Z. Q. Liu and Y. P. Du, High-quality ultralong copper sulphide nanowires for promising applications in high efficiency solar water evaporation, Mater. Chem. Front., 2019, 3, 394-398.

18 B. C. Steimle, R. W. Lord and R. E. Schaak, Phosphineinduced phase transition in copper sulfide nanoparticles prior to initiation of a cation exchange reaction, J. Am. Chem. Soc., 2020, 142, 13345-13349.

19 Y. X. Zhao, H. C. Pan, Y. B. Lou, X. F. Qiu, J. J. Zhu and C. Burda, Plasmonic $\mathrm{Cu}_{2-x} \mathrm{~S}$ nanocrystals: optical and structural properties of copper-deficient copper(I) sulfides, J. Am. Chem. Soc., 2009, 131, 4253-4261.

20 J. M. Luther, P. K. Jain, T. Ewers and A. P. Alivisatos, Localized surface plasmon resonances arising from free carriers in doped quantum dots, Nat. Mater., 2011, 10, 361-366.

21 D. X. Zhu, A. W. Tang, L. Peng, Z. Y. Liu, C. H. Yang and F. Teng, Tuning the plasmonic resonance of $\mathrm{Cu}_{2-x} \mathrm{~S}$ nanocrystals: effects of the crystal phase, morphology and surface ligands, J. Mater. Chem. C, 2016, 4, 4880-4888.

22 D. X. Zhu, A. W. Tang, Q. H. Kong, B. Zeng, C. H. Yang and F. Teng, Roles of sulfur sources in the formation of alloyed $\mathrm{Cu}_{2-x} \mathrm{~S}_{y} \mathrm{Se}_{1-y}$ nanocrystals: controllable synthesis and tuning of plasmonic resonance absorption, J. Phys. Chem. C, 2017, 121, 15922-15930. 
23 L. H. Chen, H. F. Hu, Y. Z. Chen, Y. Li, J. Gao and G. H. Li, Sulfur precursor reactivity affecting the crystal phase and morphology of $\mathrm{Cu}_{2-x} \mathrm{~S}$ nanoparticles, Chem. - Eur. J., 2021, 27, 1057-1065.

24 I. Kriegel, F. Scotognella and L. Manna, Plasmonic doped semiconductor nanocrystals: properties, fabrication, applications and perspectives, Phys. Rep., 2017, 674, 1-52.

25 F. Navarro-Pardo, L. Jin, R. Adhikari, X. Tong, D. Benetti, K. Basu, S. Vanka, H. G. Zhao, Z. T. Mi, S. H. Sun, V. M. Castano, A. Vomiero and F. Rosei, Nanofiber-supported CuS nanoplatelets as high efficiency counter electrodes for quantum dot-based photoelectrochemical hydrogen production, Mater. Chem. Front., 2017, 1, 65-72.

26 G. D. Shi, Z. X. Fan, L. L. Du, X. L. Fu, C. M. Dong, W. Xie, D. B. Zhao, M. Wang and M. J. Yuan, In situ construction of graphdiyne/CuS heterostructures for efficient hydrogen evolution reaction, Mater. Chem. Front., 2019, 3, 821-828.

27 Q. F. Feng, Y. J. Xu, B. Hu, L. An, J. M. Lin, Q. W. Tian and S. P. Yang, A smart off-on copper sulfide photoacoustic imaging agent based on amorphous-crystalline transition for cancer imaging, Chem. Commun., 2018, 54, 10962-10965.

28 R. Lesyuk, E. Klein, I. Yaremchukc and C. Klinke, Copper sulfide nanosheets with shape-tunable plasmonic properties in the NIR region, Nanoscale, 2018, 10, 20640-20651.

29 S. D. Sun, P. J. Li, S. H. Liang and Z. M. Yang, Diversified copper sulfide $\left(\mathrm{Cu}_{2-x} \mathrm{~S}\right)$ micro-/nanostructures: a comprehensive review on synthesis, modifications and applications, Nanoscale, 2017, 9, 11357-11404.

30 T.-L. Cheung, L. Y. Hong, N. X. Rao, C. B. Yang, L. B. Wang, W. J. Lai, P. H. J. Chong, W.-C. Law and K.-T. Yong, The non-aqueous synthesis of shape controllable $\mathrm{Cu}_{2-x} \mathrm{~S}$ plasmonic nanostructures in a continuous-flow millifluidic chip for the generation of photo-induced heating, Nanoscale, 2016, 8, 6609-6622.

31 D. J. Chakrabarti and D. E. Laughlin, The Cu-S (coppersulfur) system, Bull. Alloy Phase Diagrams, 1983, 4, 254-271.

32 S.-W. Hsu, K. On and A. R. Tao, Localized surface plasmon resonances of anisotropic semiconductor nanocrystals, J. Am. Chem. Soc., 2011, 133, 19072-19075.

33 S.-W. Hsu, C. Ngo and A. R. Tao, Tunable and directional plasmonic coupling within semiconductor nanodisk assemblies, Nano Lett., 2014, 14, 2372-2380.

34 L. H. Chen, M. Sakamoto, R. Sato and T. Teranishi, Determination of a localized surface plasmon resonance mode of $\mathrm{Cu}_{7} \mathrm{~S}_{4}$ nanodisks by plasmon coupling, Faraday Discuss., 2015, 181, 355-364.

35 I. Kriegel, J. R. Fernández, A. Wisnet, H. Zhang, C. Waurisch, A. Eychmüller, A. Dubavik, A. O. Govorov and J. Feldmann, Shedding light on vacancy-doped copper chalcogenides: shapecontrolled synthesis, optical properties, and modeling of copper telluride nanocrystals with near-Infrared plasmon resonances, ACS Nano, 2013, 7, 4367-4377.

36 S. K. Barman and M. N. Huda, Stability enhancement of $\mathrm{Cu}_{2} \mathrm{~S}$ against $\mathrm{Cu}$ vacancy formation by $\mathrm{Ag}$ alloying, J. Phys.: Condens. Matter, 2018, 30, 165701.
37 L.-W. Wang, High chalcocite $\mathrm{Cu}_{2} \mathrm{~S}$ : a solid-liquid hybrid phase, Phys. Rev. Lett., 2012, 108, 85703.

38 H. T. Evans, The crystal structures of low chalcocite and djurleite, Z. Kristallogr. - Cryst. Mater., 1979, 150, 299-320.

39 H. T. Evans, Djurleite $\left(\mathrm{Cu}_{1.94} \mathrm{~S}\right)$ and low chalcocite $\left(\mathrm{Cu}_{2} \mathrm{~S}\right)$ : new crystal structure studies, Science, 1979, 203, 356-358.

40 S. Djurle, An X-ray study on the system Cu-S, Acta Chem. Scand., 1958, 12, 1415-1426.

41 E. H. Roseboom, Djurleite, $\mathrm{Cu}_{1.96} \mathrm{~S}$, a new mineral, $A m$. Mineral., 1962, 47, 1181-1184.

42 N. Morimoto and G. Kullerud, Polymorphism in digenite, Am. Mineral., 1963, 48, 110-123.

43 L. G. Liu, H. Z. Zhong, Z. L. Bai, T. Zhang, W. P. Fu, L. J. Shi, H. Y. Xie, L. G. Deng and B. S. Zou, Controllable transformation from rhombohedral $\mathrm{Cu}_{1.8} \mathrm{~S}$ nanocrystals to hexagonal CuS clusters: phase- and composition-dependent plasmonic properties, Chem. Mater., 2013, 25, 4828-4834.

44 W. Georg, E. Hinze and A. R. M. Abdelrahman, Crystal structure analysis and refinement of digenite, $\mathrm{Cu}_{1.8} \mathrm{~S}$, in the temperature range 20 to $500{ }^{\circ} \mathrm{C}$ under controlled sulfur partial pressure, Eur. J. Mineral., 2002, 14, 591-598.

45 W. G. Mumme, G. J. Sparrow and G. S. Walker, Roxbyite, a new copper sulphide mineral from the Olympic Dam Deposit, Roxby Downs, South Australia, Mineral. Mag., 1988, 52, 323-330.

46 W. G. Mumme, R. W. Gable and V. Petříček, The crystal structure of roxbyite, $\mathrm{Cu}_{58} \mathrm{~S}_{32}$, Can. Mineral., 2012, 50, 423-430.

47 M. Kanehara, H. Arakawa, T. Honda, M. Saruyama and T. Teranishi, Large-scale synthesis of high-quality metal sulfide semiconductor quantum dots with tunable surfaceplasmon resonance frequencies, Chem. - Eur. J., 2012, 18, 9230-9238.

48 D.-H. Ha, A. H. Caldwell, M. J. Ward, S. Honrao, K. Mathew, R. Hovden, M. K. A. Koker, D. A. Muller, R. G. Hennig and R. D. Robinson, Solid-solid phase transformations induced through cation exchange and strain in 2D heterostructured copper sulfide nanocrystals, Nano Lett., 2014, 14, 7090-7099.

49 K. Koto and N. Morimoto, The crystal structure of anilite, Acta Crystallogr., Sect. B: Struct. Crystallogr. Cryst. Chem., 1970, 26, 915-924.

50 H. T. Evans, Copper coordination in low chalcocite and djurleite and other copper-rich sulfides, Am. Mineral., 1981, 66, 807-818.

51 S.-H. Wei, Q. Xu, B. Huang, Y. F. Zhao and R. Noufi, Stability and electronic structures of CuxS solar cell absorbers, 2012 38th IEEE Photovoltaic Specialists Conf., 2012.

52 A. M. García, A. L. Soares, E. C. Dos Santos, H. A. de Abreu and H. A. Duarte, First-principles calculations and electron density topological analysis of covellite (CuS), J. Phys. Chem. A, 2014, 118, 5823-5831.

53 W. M. Du, X. F. Qian, X. D. Ma, Q. Gong, H. L. Cao and J. Yin, Shape-controlled synthesis and self-assembly of hexagonal covellite (CuS) nanoplatelets, Chem. - Eur. J., 2007, 13, 3241-3247. 
54 H. J. Gotsis, A. C. Barnes and P. Strange, Experimental and theoretical investigation of the crystal structure of CuS, J. Phys.: Condens. Matter, 1992, 4, 10461.

55 Y. P. Du, Z. Y. Yin, J. X. Zhu, X. Huang, X.-J. Wu, Z. Y. Zeng, Q. Y. Yan and H. Zhang, A general method for the largescale synthesis of uniform ultrathin metal sulphide nanocrystals, Nat. Commun., 2012, 3, 1177.

56 R. J. Goble, The relationship between crystal structure, bonding and cell dimensions in the copper sulfides, Can. Mineral., 1985, 23, 61-76.

57 C. Coughlan, M. Ibáñez, O. Dobrozhan, A. Singh, A. Cabot and K. M. Ryan, Compound copper chalcogenide nanocrystals, Chem. Rev., 2017, 117, 5865-6109.

58 S. Conejeros, I. de P. R. Moreira, P. Alemany and E. Canadell, Nature of holes, oxidation states, and hypervalency in covellite (CuS), Inorg. Chem., 2014, 53, 12402-12406.

59 Y. Liu, M. X. Liu and M. T. Swihart, Plasmonic copper sulfide-based materials: a brief introduction to their synthesis, doping, alloying, and applications, J. Phys. Chem. C, 2017, 121, 13435-13447.

60 A. Comin and L. Manna, New materials for tunable plasmonic colloidal nanocrystals, Chem. Soc. Rev., 2014, 43, 3957-3975.

61 P. K. Jain, K. Manthiram, J. H. Engel, S. L. White, J. A. Faucheaux and A. P. Alivisatos, Doped nanocrystals as plasmonic probes of redox chemistry, Angew. Chem., Int. Ed., 2013, 52, 13671-13675.

62 L. H. Chen and G. H. Li, Functions of 1-dodecanethiol in the synthesis and post-treatment of copper sulfide nanoparticles relevant to their photocatalytic applications, ACS Appl. Nano Mater., 2018, 1, 4587-4593.

63 T. D. Sands, J. Washburn and R. Gronsky, High resolution observations of copper vacancy ordering in chalcocite $\left(\mathrm{Cu}_{2} \mathrm{~S}\right)$ and the transformation to djurleite $\left(\mathrm{Cu}_{1.97}\right.$ to $\left.{ }_{1.94} \mathrm{~S}\right)$, Phys. Status Solidi A, 1982, 72, 551-559.

64 A. Putnis, The transformation behaviour of cuprous sulphides and its application to the efficiency of $\mathrm{Cu}_{x} \mathrm{~S}$ CdS solar cells, Philos. Mag., 1976, 34, 1083-1086.

65 A. Boltasseva and H. A. Atwater, Science, 2011, 331, 290-291.

66 R. J. Mendelsberg, G. Garcia, H. Li, L. Manna and D. J. Milliron, Understanding the plasmon resonance in ensembles of degenerately doped semiconductor nanocrystals, J. Phys. Chem. C, 2012, 116, 12226-12231.

67 M. X. Liu, X. Z. Xue, C. Ghosh, X. Liu, Y. Liu, E. P. Furlani, M. T. Swihart and P. N. Prasad, Room-temperature synthesis of covellite nanoplatelets with broadly tunable localized surface plasmon resonance, Chem. Mater., 2015, 27, 2584-2590.

68 Y. Xie, L. Carbone, C. Nobile, V. Grillo, S. D’Agostino, F. D. Sala, C. Giannini, D. Altamura, C. Oelsner, C. Kryschi and P. D. Cozzoli, Metallic-like stoichiometric copper sulfide nanocrystals: phase- and shape-selective synthesis, nearinfrared surface plasmon resonance properties, and their modeling, ACS Nano, 2013, 7, 7352-7369.

69 L. H. Chen, H. F. Hu, Y. Li, R. Chen and G. H. Li, Flexible tuning of hole-based localized surface plasmon resonance in roxbyite $\mathrm{Cu}_{1.8} \mathrm{~S}$ nanodisks via particle size, carrier density and plasmon coupling, J. Mater. Sci., 2020, 55, 116-124.

70 P. L. Saldanha, R. Brescia, M. Prato, H. B. Li, M. Povia, L. Manna and V. Lesnyak, Generalized one-pot synthesis of copper sulfide, selenide-sulfide, and telluride-sulfide nanoparticles, Chem. Mater., 2014, 26, 1442-1449.

71 Y. Xie, A. Riedinger, M. Prato, A. Casu, A. Genovese, P. Guardia, S. Sottini, C. Sangregorio, K. Miszta, S. Ghosh, T. Pellegrino and L. Manna, Copper sulfide nanocrystals with tunable composition by reduction of covellite nanocrystals with $\mathrm{Cu}^{+}$ions, J. Am. Chem. Soc., 2013, 135, 17630-17637.

72 Y. Liu, M. X. Liu and M. T. Swihart, Reversible crystal phase interconversion between covellite $\mathrm{CuS}$ and high chalcocite $\mathrm{Cu}_{2} \mathrm{~S}$ nanocrystals, Chem. Mater., 2017, 29, 4783-4791.

73 M. A. Mahmoud and M. A. El-Sayed, Different plasmon sensing behavior of silver and gold nanorods, J. Phys. Chem. Lett., 2013, 4, 1541-1545.

74 Q. Zhang, N. Li, J. Goebl, Z. D. Lu and Y. D. Yin, A systematic study of the synthesis of silver nanoplates: is citrate a "magic" reagent?, J. Am. Chem. Soc., 2011, 133, 18931-18939.

75 M. Rycenga, M. H. Kim, P. H. C. Camargo, C. Cobley, Z.-Y. Li and Y. N. Xia, Surface-enhanced Raman scattering: comparison of three different molecules on single-crystal nanocubes and nanospheres of silver, J. Phys. Chem. A, 2009, 113, 3932-3939.

76 L. H. Chen, M. Sakamoto, M. Haruta, T. Nemoto, R. Sato, H. Kurata and T. Teranishi, Tin ion directed morphology evolution of copper sulfide nanoparticles and tuning of their plasmonic properties via phase conversion, Langmuir, 2016, 32, 7582-7587.

77 Y. Zhai and M. Shim, Effects of copper precursor reactivity on the shape and phase of copper sulfide nanocrystals, Chem. Mater., 2017, 29, 2390-2397.

78 T. X. Wei, Y. F. Liu, W. J. Dong, Y. Zhang, C. Y. Huang, Y. Sun, X. Chen and N. Dai, Surface-dependent localized surface plasmon resonances in CuS nanodisks, ACS Appl. Mater. Interfaces, 2013, 5, 10473-10477.

79 Y. Xie, W. H. Chen, G. Bertoni, I. Kriegel, M. Xiong, N. Li, M. Prato, A. Riedinger, A. Sathya and L. Manna, Tuning and locking the localized surface plasmon resonances of CuS (covellite) nanocrystals by an amorphous $\operatorname{CuPd}_{x} \mathrm{~S}$ shell, Chem. Mater., 2017, 29, 1716-1723.

80 N. J. Freymeyer, P. D. Cunningham, E. C. Jones, B. J. Golden, A. M. Wiltrout and K. E. Plass, Influence of solvent reducing ability on copper sulfide crystal phase, Cryst. Growth Des., 2013, 13, 4059-4065.

81 Z. N. Georgieva, M. A. Tomat, C. Kim and K. E. Plass, Stabilization of plasmon resonance in $\mathrm{Cu}_{2-x} \mathrm{~S}$ semiconductor nanoparticles, Chem. Commun., 2016, 52, 9802-9805.

82 T. Machani, D. P. Rossi, B. J. Golden, E. C. Jones, M. Lotfipour and K. E. Plass, Synthesis of monoclinic and tetragonal chalcocite nanoparticles by iron-induced stabilization, Chem. Mater., 2011, 23, 5491-5495.

83 K. H. Hartstein, C. K. Brozek, S. O. M. Hinterding and D. R. Gamelin, Copper-coupled electron transfer in colloidal 
plasmonic copper-sulfide nanocrystals probed by in situ spectroelectrochemistry, J. Am. Chem. Soc., 2018, 140, 3434-3442.

84 R. D. Schaller, M. Sykora, S. Jeong and V. I. J. Klimov, Highefficiency carrier multiplication and ultrafast charge separation in semiconductor nanocrystals studied via time-resolved photoluminescence, J. Phys. Chem. B, 2006, 110, 25332-25338.

85 W. van der Stam, S. Gudjonsdottir, W. H. Evers and A. J. Houtepen, Switching between plasmonic and fluorescent copper sulfide nanocrystals, J. Am. Chem. Soc., 2017, 139, 13208-13217.

86 L. H. Chen, H. F. Hu, R. Chen, Y. Li and G. H. Li, One-pot synthesis of roxbyite $\mathrm{Cu}_{1.81} \mathrm{~S}$ triangular nanoplates relevant to plasmonic sensor, Mater. Today Commun., 2019, 18, 136-139.

87 G. V. Hartland, Optical studies of dynamics in noble metal nanostructures, Chem. Rev., 2011, 111, 3858-3887.

88 M. Zhou, M. Tian and C. Li, Copper-based nanomaterials for cancer imaging and therapy, Bioconjugate Chem., 2016, 27, 1188-1199.

89 Y. Liu, M. Ji and P. Wang, Recent advances in small copper sulfide nanoparticles for molecular imaging and tumor therapy, Mol. Pharmaceutics, 2019, 16, 3322-3332.

90 G. Ku, M. Zhou, S. L. Song, Q. Huang, J. Hazle and C. Li, Copper sulfide nanoparticles as a new class of photoacoustic contrast agent for deep tissue imaging at $1064 \mathrm{~nm}, A C S$ Nano, 2012, 6, 7489-7496.

91 J. Mou, P. Li, C. B. Liu, H. X. Xu, L. Song, J. Wang, K. Zhang, Y. Chen, J. L. Shi and H. R. Chen, Ultrasmall $\mathrm{Cu}_{2-x} \mathrm{~S}$ nanodots for highly efficient photoacoustic imagingguided photothermal therapy, Small, 2015, 11, 2275-2283.

92 N. Balis, P. Lianos, V. Dracopoulos and K. Bourikas, Quantum dot sensitized solar cells based on an optimized combination of $\mathrm{ZnS}$, CdS and CdSe with CoS and CuS counter electrodes, Electrochim. Acta, 2013, 91, 246-252.

93 Y. B. Li, W. Lu, Q. Huang, C. Li and W. Chen, Copper sulfide nanoparticles for photothermal ablation of tumor cells, Nanomedicine, 2010, 5, 1161-1171.

94 X. G. Ding, C. H. Liow, M. X. Zhang, R. J. Huang, C. Y. Li, H. Shen, M. Y. Liu, Y. Zou, N. Gao, Z. J. Zhang, Y. G. Li, Q. B. Wang, S. Z. Li and J. Jiang, Surface plasmon resonance enhanced light absorption and photothermal therapy in the second near-infrared window, J. Am. Chem. Soc., 2014, 136, 15684-15693.

95 H. Zhu, Y. Wang, C. Chen, M. R. Ma, J. F. Zeng, S. Z. Li, Y. S. Xia and M. Y. Gao, Monodisperse dual plasmonic $\mathrm{Au} @ \mathrm{Cu}_{2-x} \mathrm{E}(\mathrm{E}=\mathrm{S}, \mathrm{Se})$ core@shell supraparticles: aqueous fabrication, multimodal imaging, and tumor therapy at in vivo level, ACS Nano, 2017, 11, 8273-8281.

96 Y. Chang, Y. Cheng, Y. L. Feng, H. Jian, L. Wang, X. M. Ma, X. Li and H. Y. Zhang, Resonance energy transferpromoted photothermal and photodynamic performance of gold-copper sulfide yolk-shell nanoparticles for chemophototherapy of cancer, Nano Lett., 2018, 18, 886-897.

97 M. Q. Sun, X. Q. Fu, K. X. Chen and H. Wang, Dualplasmonic gold@copper sulfide core-shell nanoparticles: phase-selective synthesis and multimodal photothermal and photocatalytic behaviors, ACS Appl. Mater. Interfaces, 2020, 12, 46146-46161.

98 S. H. Wang, A. Riedinger, H. B. Li, C. H. Fu, H. Y. Liu, L. L. Li, T. L. Liu, L. F. Tan, M. J. Barthel, G. Pugliese, F. De Donato, M. S. D’Abbusco, X. W. Meng, L. Manna, H. Meng and T. Pellegrino, Plasmonic copper sulfide nanocrystals exhibiting near-infrared photothermal and photodynamic therapeutic effects, ACS Nano, 2015, 9, 1788-1800.

99 J. B. Cui, Y. J. Li, L. Liu, L. Chen, J. Xu, J. W. Ma, G. Fang, E. B. Zhu, H. Wu, L. X. Zhao, L. Y. Wang and Y. Huang, Nearinfrared plasmonic-enhanced solar energy harvest for highly efficient photocatalytic reactions, Nano Lett., 2015, 15, 6295-6301.

100 Y. Wang, Z. Chen, R. G. Shen, X. Cao, Y. G. Chen, C. Chen, D. S. Wang, Q. Peng and Y. D. Li, Pd-dispersed CuS heteronanoplates for selective hydrogenation of phenylacetylene, Nano Res., 2016, 9, 1209-1219.

101 L. H. Chen, R. Chen, H. F. Hu and G. H. Li, Enhancement of photocatalytic hydrogen production of semiconductor by plasmonic silver nanocubes under visible light, Mater. Lett., 2019, 242, 47-50.

102 A. Kudo and Y. Miseki, Heterogeneous photocatalyst materials for water splitting, Chem. Soc. Rev., 2009, 38, 253-278.

103 W. Wang, M. G. Xu, X. M. Xu, W. Zhou and Z. P. Shao, Perovskite oxide based electrodes for high-performance photoelectrochemical water splitting, Angew. Chem., Int. Ed., 2020, 59, 136-152.

104 M. Wang, J. Q. Wang, C. Xi, C. Q. Cheng, C. Q. Zou, R. Zhang, Y. M. Xie, Z. L. Guo, C. C. Tang, C. K. Dong, Y. J. Chen and X. W. Du, A hydrogen-deficient nickel-cobalt double hydroxide for photocatalytic overall water splitting, Angew. Chem., Int. Ed., 2020, 59, 11510-11515.

105 N. Ghorai and H. N. Ghosh, Ultrafast plasmon dynamics and hole-phonon coupling in NIR active nonstoichiometric semiconductor plasmonic $\mathrm{Cu}_{2-x} \mathrm{~S}$ nanocrystals, J. Phys. Chem. C, 2019, 123, 28401-28410.

106 Z. C. Lian, M. Sakamoto, J. J. M. Vequizo, C. S. K. Ranasinghe, A. Yamakata, T. Nagai, K. Kimoto, Y. Kobayashi, N. Tamai and T. Teranishi, Plasmonic p-n junction for infrared light to chemical energy conversion, J. Am. Chem. Soc., 2019, 141, 2446-2450.

107 Z. Y. Zhang, J. D. Huang, Y. R. Fang, M. Y. Zhang, K. C. Liu and B. Dong, A nonmetal plasmonic Z-scheme photocatalyst with UV-to NIR-driven photocatalytic protons reduction, $A d v$. Mater., 2017, 29, 1606688.

108 Z. K. Zheng, T. Tachikawa and T. Majima, Single-particle study of Pt-modified Au nanorods for plasmon-enhanced hydrogen generation in visible to near-infrared region, J. Am. Chem. Soc., 2014, 136, 6870-6873.

109 X. Y. Cai, M. S. Zhu, O. A. Elbanna, M. Fujitsuka, S. Kim, L. Mao, J. Y. Zhang and T. Majima, Au nanorod photosensitized $\mathrm{La}_{2} \mathrm{Ti}_{2} \mathrm{O}_{7}$ nanosteps: successive surface heterojunctions boosting visible to near-infrared photocatalytic $\mathrm{H}_{2}$ evolution, ACS Catal., 2018, 8, 122-131.

110 P. Bhavani, D. P. Kumar, H. S. Shim, P. Rangappa, M. Gopannagari, D. A. Reddy, J. K. Song and T. K. Kim, 
In situ addition of $\mathrm{Ni}$ salt onto a skeletal $\mathrm{Cu}_{7} \mathrm{~S}_{4}$ integrated CdS nanorod photocatalyst for efficient production of $\mathrm{H}_{2}$ under solar light irradiation, Catal. Sci. Technol., 2020, 10, 3542-3551.

111 Q. Zhang, J. H. Zhang, L. Zhang, F. L. Yang, L. F. Li and W.-L. Dai, Black phosphorus quantum dots facilitate carrier separation for enhancing hydrogen production over hierarchical $\mathrm{Cu}_{7} \mathrm{~S}_{4} / \mathrm{ZnIn}_{2} \mathrm{~S}_{4}$ composites, Catal. Sci. Technol., 2020, 10, 1030-1039.

112 G. N. Liu, C. Kolodziej, R. Jin, S. P. Qi, Y. B. Lou, J. X. Chen, D. C. Jiang, Y. X. Zhao and C. Burda, $\mathrm{MoS}_{2}$-stratified CdS$\mathrm{Cu}_{2-x} \mathrm{~S}$ core-shell nanorods for highly efficient photocatalytic hydrogen production, ACS Nano, 2020, 14, 5468-5479.

113 M. J. Guo, T. Y. Zhao, Z. P. Xing, Y. L. Qiu, K. Pan, Z. Z. Li, S. L. Yang and W. Zhou, Hollow octahedral $\mathrm{Cu}_{2-x} \mathrm{~S} / \mathrm{CdS} /$ $\mathrm{Bi}_{2} \mathrm{~S}_{3}$ p-n-p type tandem heterojunctions for efficient photothermal effect and robust visible-light-driven photocatalytic performance, ACS Appl. Mater. Interfaces, 2020, 12, 40328-40338.

114 K. X. Ren, P. F. Yin, Y. Z. Zhou, X. Z. Cao, C. K. Dong, L. Cui, H. Liu and X. W. Du, Localized defects on copper sulfide surface for enhanced plasmon resonance and water splitting, Small, 2017, 13, 1700867.

115 B. C. Marin, S.-W. Hsu, L. Chen, A. Lo, D. W. Zwissler, Z. W. Liu and A. R. Tao, Plasmon-enhanced two-photon absorption in photoluminescent semiconductor nanocrystals, ACS Photonics, 2016, 3, 526-531.

116 C. F. Wu, C. Szymanski, Z. Cain and J. McNeill, Conjugated polymer dots for multiphoton fluorescence imaging, J. Am. Chem. Soc., 2007, 129, 12904-12905.

117 W. Denk, J. H. Strickler and W. W. Webb, Two-photon laser scanning fluorescence microscopy, Science, 1990, 248, 73-76.

118 D. L. Zhou, D. L. Liu, W. Xu, Z. Yin, X. Chen, P. W. Zhou, S. B. Cui, Z. G. Chen and H. W. Song, Observation of considerable upconversion enhancement induced by $\mathrm{Cu}_{2-x} \mathrm{~S}$ plasmon nanoparticles, ACS Nano, 2016, 10, 5169-5179.

119 D. L. Zhou, D. Y. Li, X. Y. Zhou, W. Xu, X. Chen, D. L. Liu, Y. S. Zhu and H. W. Song, Semiconductor plasmon induced up-conversion enhancement in $\mathrm{mCu}_{2-x} \mathrm{~S} @ \mathrm{SiO}_{2} @ \mathrm{Y}_{2} \mathrm{O}_{3}$ : $\mathrm{Yb}^{3+} / \mathrm{Er}^{3+}$ core-shell nanocomposites, ACS Appl. Mater. Interfaces, 2017, 9, 35226-35233.

120 D. L. Zhou, D. L. Liu, W. Xu, X. Chen, Z. Yin, X. Bai, B. Dong, L. Xu and H. W. Song, Synergistic upconversion enhancement induced by multiple physical effects and an angle-dependent anticounterfeit application, Chem. Mater., 2017, 29, 6799-6809.

121 W. G. Xu, J. Q. Xiao, Y. F. Chen, Y. B. Chen, X. Ling and J. Zhang, Graphene-veiled gold substrate for surface-enhanced Raman spectroscopy, Adv. Mater., 2013, 25, 928-933.

122 M. Masetti, H.-N. Xie, Ž. Krpetic, M. Recanatini, R. A. A. Puebla and L. Guerrini, Revealing DNA interactions with exogenous agents by surface-enhanced Raman scattering, J. Am. Chem. Soc., 2015, 137, 469-476.

123 W. H. Li, R. Zamani, P. R. Gil, B. Pelaz, M. Ibáñez, D. Cadavid, A. Shavel, R. A. A.-Puebla, W. J. Parak, J. Arbiol and A. Cabot, CuTe nanocrystals: shape and size control, plasmonic properties, and use as SERS probes and photothermal agents, J. Am. Chem. Soc., 2013, 135, 7098-7101.

124 S. Cong, Y. Y. Yuan, Z. G. Chen, J. Y. Hou, M. Yang, Y. L. Su, Y. Y. Zhang, L. Li, Q. W. Li, F. X. Geng and Z. G. Zhao, Noble metal-comparable SERS enhancement from semiconducting metal oxides by making oxygen vacancies, Nat. Commun., 2015, 6, 7800.

125 Y. Y. Qiu, M. Lin, G. X. Chen, C. C. Fan, M. W. Li, X. J. Gu, S. Cong, Z. G. Zhao, L. Fu, X. H. Fang and Z. Y. Xiao, Photodegradable CuS SERS probes for intraoperative residual tumor detection, ablation, and self-clearance, ACS Appl. Mater. Interfaces, 2019, 11, 23436-23444.

126 M. L. Chen, K. Li, Y. Y. Luo, J. P. Shi, C. C. Weng, L. Gao and G. T. Duan, Improved SERS activity of non-stoichiometric copper sulfide nanostructures related to charge- transfer resonance, Phys. Chem. Chem. Phys., 2020, 22, 5145-5153.

127 H. M. Bao, H. W. Zhang, L. Zhou, H. Fu, G. Q. Liu, Y. Li and W. P. Cai, Ultrathin and isotropic metal sulfide wrapping on plasmonic metal nanoparticles for surface enhanced Ram scattering-based detection of trace heavy-metal ions, ACS Appl. Mater. Interfaces, 2019, 11, 28145-28153.

128 Y. Xie, G. Bertoni, A. Riedinger, A. Sathya, M. Prato, S. Marras, R. Y. Tu, T. Pellegrino and L. Manna, Nanoscale transformations in covellite (CuS) nanocrystals in the presence of divalent metal cations in a mild reducing environment, Chem. Mater., 2015, 27, 7531-7537.

129 P. Kumar and R. Nagarajan, An elegant room temperature procedure for the precise control of composition in the Cu-S system, Inorg. Chem., 2011, 50, 9204-9206.

130 W. Imaino, C. T. Simpson, W. M. Becker and A. K. Ramdas, Resonant Raman effect in cinnabar, Phys. Rev. B: Condens. Matter Mater. Phys., 1980, 21, 634-642. 